\title{
Women's interest development and motivations to persist as college students in STEM: a mixed methods analysis of views and voices from a Hispanic-Serving Institution
}

Kimberly Grau Talley and Araceli Martinez Ortiz

\begin{abstract}
Background: The constructs of interest and motivation are often identified as factors that contribute to the persistence of undergraduate college women in physics, mathematics, engineering, engineering technology, and computer science. A review of the literature regarding interest development and motivation as related to women as science, technology, engineering and mathematics (STEM) learners in diverse communities is presented. The goal of this study was to gain a deeper understanding of the experiences women credited for influencing the development of their career interest goals and the sources of motivation they attribute to success in their academic course outcomes in their fields of study.

Results: A mixed methods research approach was used to collect student perceptions related to interest and motivation by collecting data through the use of questionnaires and conducting focus groups. Results indicated that students identify early participation in STEM activities and family socializing behavior as ones that contributed the most towards influencing their interest in STEM and motivated them to persist in their studies and pathways as future STEM professionals.

Conclusions: This study is unique in that the participant groups included a substantial representation of Latina and African American women's voices as relayed through the collected quantitative data as well as through the use of focus groups that encouraged women to freely identify experiences they felt contributed to their persistence success. These women identify interest development at various points in their lives as affected by family and school experiences, and family support was identified as having greater importance in their decision to persist.
\end{abstract}

Keywords: Women in STEM, STEM fields of study, Interest, Motivation, Undergraduate persistence, Latina, Hispanic, African American, College students

\footnotetext{
* Correspondence: amo56@txstate.edu

Texas State University, San Marcos, TX, USA
} 


\section{Background}

While some may debate the exact workforce statistics regarding the USA's need for more science, technology, engineering and mathematics (STEM) professionals (President's Council of Advisors on Science and Technology 2012; Carnevale et al. 2010; Lowell and Salzman 2007; Teitelbaum 2014), it is clear that women continue to be underrepresented in this group. Women earn less than $20 \%$ of bachelor's degrees in computer science and engineering and constituting less than $15 \%$ of all working engineers in the USA according to the National Science Foundation, National Center for Science and Engineering Statistics (2015) This underrepresentation is detected well before women reach the career level (Hill et al. 2010) and may be related to interest and selfconcept (Seymor 1995; Jacobs, Lanza, Osgood, Eccles, and Wigfield 2002), as well as to institutional factors (Griffith 2010). Furthermore, Eccles (1987) has argued that these differences result from both differential expectations for success and differences in gender-role socializations. Therefore, it is urgent that this issue be studied at the higher education level.

In order to support in the academic preparation and production of a larger and more diverse pool of scientists and engineers, there continues to be a need to better understand how the psychosocial constructs of interest and motivation drive the success of students pursuing academic degrees in STEM. This study is part of a larger student retention effort at Texas State University, a large, Hispanic-Serving Institution committed to this goal. As such, this study was undertaken to gain a deeper understanding of what experiences women credited for influencing the development of their career interest goals and their motivation to succeed in academic courses related to studying in a STEM field. As this study was conducted at a Hispanic-Serving Institution (HSI), it involves a unique and diverse audience versus the majority of related studies reviewed in the existing literature. It includes a substantial representation of Latina and African American women as part of the participant sample, and their voices are carefully represented and analyzed to identify experiences that appear to contribute to student interest development and motivation. A nearly even mix of white and minority (including Latina, African American, and multi-racial) students additionally allows comparisons within the same institution for differences between student ethnic groups.

\section{Retention theories}

When college student retention theories first evolved 45 years ago, the issue was viewed through the lens of psychology. Student retention was thought to be a function of individual motivation, attributes, and skills; thus, students failed, not institutions (Tinto 2006).
From the 1970s onward, this view of retention yielded to one focused on the relationship between students and society. As a result, greater emphasis was placed on the role of institutions in students' decisions on whether to stay or leave (Spady 1971). Since then, several major theories/models have tried to explain student retention/attrition; Seidman (2005) provides a broad overview of as many as eight retention theories. Tinto's model paved the way for a sociological analysis of retention that has been popular for several decades (Noel-Levitz 2012), and it postulates that persistence occurs when students successfully integrate into the institution academically and socially. Integration, in turn, is influenced by pre-college characteristics and goals, interactions with peers and faculty, out-of-classroom socialization, and personal family dynamics and acculturation factors (Jensen 2011). Additionally, Tinto argues that the first year of college is critical to students being incorporated into the college campus, as well as their eventual persistence to graduation. Retention programs, therefore, are most successful when they utilize informal faculty-student contact in order to integrate students into the academic and social life of the college (Longwell-Grice and Longwell-Grice 2007).

Some studies have examined the effect of precollege characteristics, parental socialization, and college experiences to determine their relationship to female STEM major persistence. In a study by Espinosa (2011), the experiences of 1250 women of color and 891 Caucasian women attending 135 colleges nationwide were collected via a reflective $q$ of their 4 years of study and post baccalaureate goals. Results of the study showed that the role of women's college experiences was most paramount in the persistence of STEM majors (Espinosa 2011). Women of color who persisted in STEM engaged more often with peers to discuss course content, joined STEM-related student organizations, participated in undergraduate research programs, had altruistic ambitions, attended private colleges, and attended schools with a thriving community of STEM students. Ong et al. (2011) reviewed nearly 40 years of research on postsecondary educational experiences of women in STEM majors. Their synthesis of 116 research studies provides insight in the factors that influence the retention, persistence, and achievement of women of color in STEM majors and careers. Some of the factors they found to influence the undergraduate experiences of women of color in STEM persistence were STEM enrichment programs, interactions with peers and faculty, academic sense of self, and personal agency and drive.

\section{Interest and motivation}

At its core, the study of motivation is simply the pursuit to understand why people behave as they do, or to 
understand "the reasons underlying behavior" (Guay et al. 2010, p. 712). There are many theories of motivation. Content theories such as those by Maslow (1943), Alderfer (1972), Herzberg (1966), and McCelland (1985) deal with "what" motivates people; their individual needs and goals. Process theories such as expectancy theory by Vroom (1964), goal theory by Locke and Latham (1990), and equity theory by Adams (1963) attempt to explain how and why motivation happens. Reinforcement theories, such as those rooted in Skinner's (1953) behaviorism, attempt to explain how outcomes influence behavior. In the field of workplace motivation, Scholl (2015) describes motivation as "the force that energizes, directs, and sustains behavior." This definition includes three aspects that help to guide the inquiry to explain the amount of energy an individual puts into a task, the direction of one's effort based on choice and conflict, and finally, the issue of persistence and consistency of behavior. Pintrich and Schunk (2002, p.4) define motivation as "the process whereby goal-directed activity is instigated and maintained." This definition forms the basis upon which other nuances of goal-directed behavior are studied. This foundation is particularly important when analyzing sustained motivation, as was done by Hernandez et al. (2013), in a longitudinal study with racially and ethnically diverse STEM discipline university students. After following over 1000 students for 3 years, monitoring both the individual and environmental factors and the influence that these factors had upon students' individual and longitudinal regulation of goals and resulting academic performance, the findings in this particular study supported the hypothesis that students do indeed align their goals to the context of STEM academic learning, and this adaptation influences their performance and ultimately their success and persistence in STEM.

Another integrative model of motivation is described by Leonard et al. (1999) and includes five sources of motivation. These elements include "intrinsic process motivation," in which individuals are motivated by tasks that are intrinsically enjoyable, but risk losing motivation when the intrinsic motivator is removed. The second element is "instrumental motivation," in which individuals believe that their behaviors are the vehicle or instrument that will lead to certain outcomes such as good grades, internships, and job offers. The third element is "external self-concept-based motivation," in which the source of motivation is external and directed by the role expectations of reference groups as driven by the need for acceptance and status. The fourth element is "internal self-concept-based motivation" in which the individual is self-directed and has a high need for achievement. Inner-driven individuals are motivated by task feedback regarding their efforts as being vital in achieving important outcomes. The fifth element is "goal internalization" in which individual's value system is aligned to internal attitudes and behaviors that lead to belief in the cause and work towards the goals that support the cause. This framework will serve to guide the theoretical basis of our proposed study, since it also will make use of a validated instrument comprised of a set of questionnaires to measure motivation (Barbuto and Scholl 1998).

Cognitive and developmental psychologists have been studying the concept of "interest" as part of the study of learning and learning motivation for over a century (Dewey 1913). When seen as an intrinsic force, interest motivates the seeking of knowledge for its own sake. It can also be thought of as a natural or emotional predisposition to engage with particular ideas, activities, or physical objects, and the experience of interest is the key to achieving intrinsically motivated learning (Silvia 2006). Silvia posits that interest can both focus and diversify our experiences, as interest sometimes narrows our choices, while other times leads us to pursue new and larger related experiences stemming from the original interest. Interest is an emotional motivator that affects learning by stimulating the use of deeper processing strategies. In the field of reading for example, researchers have found that people who find a text interesting are able to connect the material more thoroughly to other knowledge and thus remember it better (Sadoski and Paivio 2001; Schiefele 1999). Thus, interest may be a critical cognitive and affective motivational variable that guides attention and facilitates learning (Renninger and Wozniak 1985; Denissen et al. 2007), develops through experience (Azevedo 2005; Krapp and Lewalter 2001) and influences career choice (Lent et al. 2008).

\section{Female persistence in collegiate STEM programs}

The so-called "leaky-pipeline" metaphor describes the various points along the $\mathrm{K}-16$ academic pipeline at which participants move away from or "leak" out of the preparation process. This issue describes the pathway choices that are particularly representative of women, as will be described in the following section.

It has been popularly accepted that boys prefer construction toys and girls prefer doll-like toys (Connor and Serbin 1977) and that these seemingly genetic tendencies manifest themselves into future career choices. For example, current data at universities like Texas State University reveal that even within the field of STEM, women are more likely to pursue a natural science major versus a physical science major (Martinez Ortiz and Sriraman 2015), and there is certainly a gap in the gender representation of men and women in the STEM workforce. According to the Science and Engineering Indicators report (National Science Foundation 2016), although women 
represent $50 \%$ of the total US college-educated workforce, they only represent $15 \%$ of the engineering workforce. Investigation of the factors contributing to this leaky pipeline leads us to explore more deeply the literature examining women's interest and motivation in STEM, from a cognitive and psychosocial perspective. For example, Eccles (1987) has argued that the differences in career choice for women result from both differential expectations for success and differences in gender-role socializations while researchers like Backer and Halualani (2012) focus on the contribution of the cognitive construct of self-efficacy. Self-efficacy is defined by Bandura (1995, p.2) as "the belief in one's capabilities to organize and execute the courses of action required to manage prospective situations." It has been argued that self-efficacy can be a predictor of academic achievement (Bandura and Locke 2003) and persistence (Lent et al. 2003). Backer and Halualani explore the impact of student self-efficacy on interest and choice by female engineering students at California University with declining participation by women in undergraduate engineering programs. They found seemingly conflicting results because, despite their declining numbers, the self-efficacy levels of the remaining women were high. Perhaps if they had examine the self-efficacy of the women who did not persist in engineering, they may have found lower levels of self-efficacy in engineering fields of study or other contributing environmental or institutional factors.

Scholars such as Bettinger and Long (2005) have examined environmental factors such as the role of faculty members as role models and found that instructor attributes may affect student interest. Griffith (2010) explored if the institution mattered or affected persistence of women and minorities in STEM by examining National Educational Longitudinal data sets. Her findings suggested that, indeed, institutional characteristics affect persistence as evidenced by higher student persistence rates at institutions with higher proportions of undergraduate students versus graduate students. Finally, Szelehnyi, Denson, and Inkelas (2013) examine student outcomes related to women who are STEM majors who participate in living-learning programs. Their findings also indicate that such a college environment also influences professional outcome expectations.

Therefore, utilizing this literature base, our study was undertaken to further probe multiple factors using a methodology that allowed for both a quantitative and qualitative assessment.

\section{Aim}

The goal of this study was to gain a deeper understanding of what experiences women credited for influencing their career interest goals and their motivations to succeed in academic courses of their chosen science, technology, engineering and mathematics (STEM) fields. The two specific research questions addressed in this paper are:

1. What factors contribute to the interest development and motivational drive to persist of college women in STEM?

2. In what ways, if any, do Latina and African American STEM students differ in their interest development and motivations to persist in STEM from their White female peers?

\section{Methods}

\section{Study design}

This study utilizes a mixed methods approach to research by incorporating quantitative and qualitative research approaches in a single research study. This mixing of data allows for a more complete and synergistic exploration of data and allows for the qualitative data to be used to explore the quantitative findings (Creswell and Plano Clark 2011). This study design also allows for the greater understanding of the research problem by obtaining different but complementary data.

In order to address the research question(s) defined, the survey methodology used incorporated a questionnaire containing closed-ended questions coupled with focus group methodology using open-ended questions to collect the narrative, or qualitative, data. The main two constructs, "interest" and "motivation", were explored in this study and are tied directly to the research questions. The case for the overall construct validity was seriously considered and was operationalized through survey and interview questions based on definitions of the constructs and the theoretical bases discussed above. The mixed methods research study presented here utilized qualitative and quantitative techniques to integrate findings and to support inferences to provide deep understanding of the student insights and motivations under investigation. This study used a combination of an online questionnaire and interview data from five focus groups in order to identify contributing factors and trends between and within groups from the larger subset of students $(n>50)$ as well as to gain in-depth responses from a smaller group of students $(n<25)$. Therefore, a mixed methods research study was used that combined the use of an online questionnaire for quantitative analysis and five focus groups for qualitative analysis. The questions for both instruments were selected and modified based upon published studies by Hughes (2010), Chang et al. (2014), Edzie (2014), Martinez Ortiz and Sriraman (2015), and Pintrich and DeGroot (1990). These instruments were selected as they are in use with other populations and/or at other institutions. This correspondence 
with the modified instrument developed for this study allows for a future effort in comparing results at a national level. As well, the inclusion of validated quantitative instruments (Pintrich et al. 1993) will facilitate the future work of establishing the validity of the questions in the Edzie instrument. The Edzie questionnaire was used as the primary source for the development of the Identity and Culture in STEM Persistence Survey (ICSTEM Persistence Survey). Select questions from the ICSTEM questionnaire, as from the focus group, were chosen to narrow the discussion to "interest development and motivation development"; the themes of this paper.

\section{The questionnaire}

The measurement tool used in this study was a modified version of the questionnaire utilized by Edzie (2014) as part of a mixed methods dissertation relevant to this study. Edzie developed a 15-question survey instrument based on the "self-efficacy for learning and performance" motivation subscale of the Motivated Student Learning Questionnaire (Pintrich and DeGroot 1990, Pintrich et al. 1993) and additional qualitative research findings. Edzie used the instrument to gather undergraduate student data regarding student self-efficacy as compared to pre-collegiate factors potentially contributing to STEM persistence. Although Edzie's work was conducted at Midwestern University, amongst a population of predominately white students, the questionnaire includes probing questions relevant across race and cultural experience. Further, the groupings of questions focused on students' motivations to persist and factors in choosing their majors, which echo portions of the validated Motivational Sources Inventory (MSI) (Barbuto and Scholl 1998). We selected to use this instrument due to the relevant content of the questions and due to the inclusion of validated scales from Pintrich et al. (1993) and Barbuto and Scholl (1998). Also, by administering Edzie's questionnaire at Texas State University, a university with a significant minority student population $(47 \%$ minority or multiracial in Fall 2014), the results from the two universities can be compared in detail in a future analysis report.

\section{Setting}

The study took place at a large university in Texas State. It is a growing and vibrant emerging research university designated as a Hispanic-Serving Institution. In Fall 2014, Hispanics made up $33 \%$ of the undergraduate population, African-American students made up 8\%, and White students represented $51 \%$ of the population. This highly diverse student body provided rich opportunities to identify experiences that appear to contribute to Latina and African-American STEM identity and self-confidence development as well as to explore any differences in this development versus their white female peers. In Fall 2014, STEM majors constituted about $7 \%$ of the overall undergraduate student population at Texas State (2308 of 32,522). About $40 \%$ of those STEM undergraduates were Hispanics and African Americans and 10\% were females.

\section{Characteristics of participants}

The sampling method for this study was non-probability sampling based on a voluntary sample from a targeted population group. This voluntary sample was made up of people who self-selected into the study. The population of interest was women from four departments in the College of Science and Engineering with low percentages of female majors: Computer Science, Engineering Technology, Engineering, and Physics. Women majoring in these departments that were ranked as juniors, seniors, or graduate students for the 2013-2014 or 2014-2015 academic years were invited to participate. Some underclassman students heard about the study from word of mouth and also participated. Formally, participants were recruited by developing a database of women meeting the criteria above and inviting them to participate by participating in both an online questionnaire and participating in a focus group. Participants were recruited via email. Email invitations were sent from the research team, a faculty member in each department, and through peer leaders of the SWE (Society for Women Engineers) organization. The email invitations containing the link to the questionnaire also invited the students to participate in the focus groups. Participation in a focus group required a greater time commitment than an online questionnaire, so students were offered a small monetary research incentive for completing both the online questionnaire and participating in the focus group session. As such, the focus group population is also part of the survey population. To further encourage student participation and to establish a welcoming environment, the focus group sessions included refreshments and were held in a location familiar to the students.

\section{ICSTEM Persistence Questionnaire}

The online ICSTEM Persistence Questionnaire was developed and hosted through an online questionnaire tool (Survey Monkey) for easy access to the participants. This questionnaire utilized questions from Edzie (2014) and questions asked of faculty during the university's selfstudy in Fall 2013 (Martinez Ortiz and Sriraman 2015). The Edzie questionnaire also contained a portion of the Motivated Strategies for Learning Questionnaire, a widely used self-report instrument that measures student motivation and learning strategies at the subject domain level (MSLQ) (Pintrich and DeGroot 1990, Pintrich et al. 
1991, and Pintrich et al. 1993). Specifically, the ICSTEM Persistence Questionnaire contained the "self-efficacy for learning and performance" motivation subscale of the MSLQ. Further, the questions on choice of major and motivations to persist in major reflect several subscales within the validated MSI (Barbuto and Scholl 1998). Most of these related statements draw upon aspects of the "internal self-concept" subscale of the MSI, although there also some statements relating to each of three additional MSI subscales: "intrinsic process", "instrumental", and "external self-concept." While the questionnaire technically had 30 questions, some of these questions were to evaluate a list of statements on a Likert scale. Thus, the questionnaire featured 22 questions that were yes/ no or selections from a list, seven questions asking students to rank statements with a Likert scale (65 statements in total), and an open-ended request for two recommendations of how to increase STEM major retention.

\section{Focus groups}

One of the aims of this research was to gain an in-depth understanding of student behavior and to identify some of the reasons that govern such behavior. Therefore, it was important to utilize a qualitative research methodology that would provide the insight into the motivation and feelings of these students. Towards this end, smaller focused samples of data providing this insight were collected through a series of five focus group sessions. A focus group is a form of qualitative research in which groups of people are asked about their perceptions, opinions, beliefs, and attitudes towards a concept (Krueger 1994; Krueger and Casey 2000). The use of a focus group acknowledges the importance of looking at variables in a natural setting and allows the interviewer to establish a safe environment in which the participants feel comfortable enough to share personal information. An interviewer or moderator uses a question guide to pose questions in an interactive group setting where participants are free to respond in order or in free form, and they can talk with other group members. Detailed data was gathered through eight openended questions that allowed students to provide direct quotations. Some of the drawbacks to conducting a focus group are the amount of time required in conducting it and the small number of participants that can be involved at a time; however, the advantages include high-quality insights revealed through the interaction of the group and enhanced memories and experiences shared by participants as a result of the group dynamic (Lindlof and Taylor 2002).

The focus group sessions were designed to last about $1 \mathrm{~h}$ and used a question guide with eight questions developed to probe the key areas based on a review of the literature and interview questions developed for similar studies by Hughes (2010), the findings of Chang et al. (2014), and the validated Motivational Sources Inventory (MSI) (Barbuto and Scholl 1998). The first three questions of the focus group were developed to explore the constructs of interest and motivation and are presented below, along with their derivative question from the validated MSI instrument. The full focus group question guide is presented in Table 1. Each question is actually comprised of a series of related subquestions that aim to explore the individual's interests and motivation: (1) The first question explored "intrinsic process" motivation sources. The participant was asked to talk about themselves, their personality, and the types of activities they consider fun and that bring them joy. If the student described their motivation to pursue STEM fields of study for the pure fun of it, then it could be concluded that intrinsic process motivation is taking place. Students were also asked to explain their rationalization (motivation) for having selected to pursue academic studies in Science, Technology, Engineering, or Math; (2) The second question asked students to explore their "external self-concept" motivation sources to understand if external systems such as public, family, or peer recognition are the motivator. An externally motivated person's behavior is most often driven to satisfy an external reference group. This set of questions also explored student's explanation of their interest development in STEM;

Table 1 Focus questions in focus group guide

\begin{tabular}{l}
\hline Question Number Focus Question \\
\hline Please tell us a little bit about your self- How would \\
you define your personality? What do you enjoy \\
doing most? How does Science, Technology, \\
Engineering or Math fit in with that definition? \\
How long have you been interested in STEM? Was \\
there a particular experience that you can remember \\
that sparked that interest as a child, middle and \\
high school student, and now college? If yes, can \\
you please explain? \\
Describe yourself as a student. What was your \\
original declared major? What is your major now? \\
What are your best subjects? Why? What are your \\
least favorite subjects? Why? \\
How would you define the culture of the university/ \\
department/program? Please comment on the role \\
of faculty in creating this culture. Has this culture \\
influenced your decision to pursue and or persist in \\
a STEM major? Any specific examples? \\
Do you know other women at Texas State that were \\
pursuing a STEM field of study but then changed majors \\
before completing? Do you have any ideas of the kinds \\
of issues that may have caused them to change? \\
Over 50\% of the students at Texas State are women, \\
but only 20\% of the students in STEM are women. \\
Why do you think more women are not here? \\
In what ways has your family been a support (or \\
not) to you regarding pursuing your career choice? \\
Do you think there are barriers to women with \\
careers in STEM? Why? Do you think this is \\
changing? Why? \\
What do you think of current programs on campus \\
and across the country that aim to increase the \\
number of women in STEM fields? What is the most \\
important action that Texas State University can take \\
to increase the number of women who graduate with \\
STEM degrees? Are you in any mentorship programs?
\end{tabular}


(3) The third set of questions explored "internal selfconcept" motivation sources by asking questions to understand if the individual was primarily innerdirected. Such inner-direction occurs when the individual develops their unique set of standards and values that are then used as a touchstone for decision making towards the ideal self.

\section{Limitations}

The limitations of this study can be grouped into two categories: participants and instruments. The participants involved were self-selected and volunteered to share their opinions and thus may not reflect all of the voices in the college. As well, the statistical power of the statistically significant differences between the minority and white participant samples ranged from 42 to $70 \%$ depending on the question. The statistical power can be increased with a larger sample size. Further, the focus groups were conducted with a random set of students representing a diverse mix of academic majors, ages, and ethnicities. This unfamiliarity with the group members may have led some participants to not share their open opinions. Focus groups also had the risk of an outspoken participant dominating the conversation, although the facilitators consciously made the effort to draw out quieter members to give all a chance to share their opinions. The other limitation of this study is that the standalone ICSTEM composite questionnaire and the focus group guide have not yet been validated. These survey instruments were based upon two validated scales for measuring motivation (with language modifications) and have established face validity; however, language has been altered and reorganized. Therefore, researchers plan to utilize this first collection of data as a pilot test to identify underlying components, to verify internal consistency, and will continue collecting data using these instruments to both increase statistical power and inform changes towards the creation of a valid instrument.

\section{Results}

As has been described, both qualitative and quantitative data was collected using focus groups as well as survey methodology. All student participants who formed part of the focus groups also participated in completing the questionnaire. The intent of using both of these methods was not to seek confirmation and alignment but rather to expand and present complementary findings and more in-depth insights.

\section{Qualitative focus group data-thematic analysis}

Five focus group sessions were held during the 8-month period of this study. The number of participants at each session ranged from 2 to 9 women, for a total of 25 participants. Of the focus group participants $(N=25), 56 \%$ identified themselves as White, non-Hispanic, and the rest $(44 \%)$ as a minority or multi-racial, including $36 \%$ Hispanic and 12\% African-American students (one student selected both Hispanic and African American).

The eight groups of focus questions from the guide are shown in Table 1. The first three sets of questions of the focus group were developed to explore the constructs of interest and motivation. These questions sought to explore interest development, intrinsic process sources of motivation, external process sources of motivation, and internal self-concept sources of motivation. For this analysis, a deductive thematic analysis (Daly et al. 1997) was used to search for emerging themes judged as being important to the description of the constructs of interest and motivation. Such an analysis is a form of pattern recognition within the interview data towards the identification of overarching themes that relate back to the constructs.

\section{Intrinsic process sources of motivation}

The following table (Table 2) presents a summary of the coded subthemes within the intrinsic process source of motivation:

One of the underlying motives for this set of questions was to understand how women in this study described their personality and whether they made any connections between their intrinsic sources of motivation and their choice and interest in STEM fields of study. The following selected quotes from a longer transcript (using speaker pseudonyms) reveal some of the variety in personality descriptions and intrinsic motivation sources:

Response highlights from question set \#1

Table 2 Emergent themes related to intrinsic process sources of motivation

\begin{tabular}{|c|c|c|}
\hline Construct & Theory-driven codes & $\begin{array}{l}\text { Interview emergent } \\
\text { subthemes }\end{array}$ \\
\hline $\begin{array}{l}\text { Intrinsic } \\
\text { process } \\
\text { motivation }\end{array}$ & $\begin{array}{l}\text { The individual is motivated by } \\
\text { the fun or joy of the task. } \\
\text { The work is the motivator. } \\
\text { Intrinsically motivated behavior } \\
\text { is a continuous process of } \\
\text { seeking and overcoming } \\
\text { challenges in order to arrive at } \\
\text { the intrinsic satisfaction or fun. }\end{array}$ & $\begin{array}{l}\text { Student reveals love for } \\
\text { building, creativity, or } \\
\text { problem solving. } \\
\text { Students discuss the joy } \\
\text { and fun they attribute to } \\
\text { doing the work of STEM } \\
\text { academic study—the } \\
\text { math, the coding, and } \\
\text { the designing. } \\
\text { Students discuss the } \\
\text { pride they feel in being } \\
\text { resilient and seek to } \\
\text { "conquer" STEM classes } \\
\text { in order to arrive at the } \\
\text { point where they can } \\
\text { "do" the engineering } \\
\text { things that make them } \\
\text { happy. }\end{array}$ \\
\hline
\end{tabular}


Anisa: I am independent and like to stand out. As a girl in engineering, I stand out / it's easier to stand out. I like to be better than the guys. I like to know (that) I'm better than guys. I'm a girl and the best, so I stand out.

Anisa expresses a strong drive to be the best and attributes her gender as an identity element that lets her and others know she is the best.

Ellie: I'm joking and sarcastic. I'm curious; I want to know how things work. I want to learn why things happen. I would be a professional student if I could and not be in debt the rest of my life. But can also be very lazy at times. Like, I could get A's if I applied myself more.

Ellie identifies with the characteristic of curiosity and her love of learning as part of her personality and her interest in STEM. She states that her curiosity makes her want to learn how and why things work. This curiosity is an intrinsic process motivator.

Carina: I'm basically... I'm very bubbly, and very outspoken in a way. I've been told I am resilient, and I didn't know what that was, so I had to look it up. I found a lot of meanings about it, one of them is actually like $a$, an example is pulling a spring and having it bounce back. I go oh, there goes engineering right there, that's science. Cool, I'm relating to both I guess.

Carina shares her discovery of the word "resilience" and presents it now with pride as not only an identifying word about her but also as an interesting science phenomena. By describing herself this way, she reveals an intrinsic satisfaction with being a resilient and outspoken learner.

Ana: I'm a people person. I really like making things run efficiently, for things to work effectively. I don't like things to be broken, and so I wanted to apply that to people and to companies and organizations.

Ana discusses how she does not like things to be broken. She describes her personality as one that wants to improve things for people and larger organizations. She reveals her intrinsic motivation for wanting to help.

Stacey: I'm very outgoing and I love meeting new people. I love art, I love building things out of nothing, I love math- I get a math test and I get excited!

Stacey describes her outgoing personality and love for building out of nothing as a good match for STEM learning. She also shares her love for mathematics and the intrinsic fun and joy she gets in doing this kind of work.

Gabriela: I like everything neat and all in its place code is neat and perfect and all in its place so that fits well with my personality.

Gabriela likens her preference for order and neatness and a close link to her engineering field of study. Her intrinsic motivation is to satisfy her desire for order.

Overall analysis revealed that even those women who described themselves as introverts, revealed an inner independence and curiosity intrinsic to their personality that aligned to their particular personal skills (organization, problem solving, technology, etc.) and saw this as a good fit to their chosen field of study. They are motivated to pursue a STEM field because they recognize an inner satisfaction or intrinsic motivation that drives them to persist.

\section{External self-concept source of motivation}

The following section and table (Table 3) present a summary of the coded subthemes within the strand of external self-concept motivation. One of the underlying motives for this set of questions was to understand how women in this study described experiences that hinted at connections between external influences and people and their interest and motivation to pursue a STEM field of study. The following selected quotes from a longer transcript (using speaker pseudonyms) reveal the variety in responses regarding external self-concept sources of motivation.

Response highlights from question set \#7

Table 3 Emergent themes related to external self-concept processes of motivation

\begin{tabular}{|c|c|c|}
\hline Construct & Theory-driven codes & Interview emergent subthemes \\
\hline $\begin{array}{l}\text { External } \\
\text { self-concept } \\
\text { motivation }\end{array}$ & $\begin{array}{l}\text { Important that others } \\
\text { approve of individual's } \\
\text { behavior. } \\
\text { Decisions are made } \\
\text { based on what others } \\
\text { think. } \\
\text { Motivated to work } \\
\text { harder if public } \\
\text { recognition is attached. } \\
\text { Need for external } \\
\text { recognition and social } \\
\text { connections. }\end{array}$ & $\begin{array}{l}\text { Students are interested in } \\
\text { receiving external affirmation } \\
\text { deriving mostly from family. } \\
\text { Students feel a responsibility } \\
\text { to succeed and earn a good } \\
\text { living to meet the } \\
\text { expectations of family. } \\
\text { Students discuss the desire to } \\
\text { fulfill external expectations } \\
\text { deriving from their ethnic } \\
\text { cultures and the pride they } \\
\text { feel when they are able to } \\
\text { respond to these expectations. }\end{array}$ \\
\hline
\end{tabular}


In what ways has your family been a support (or not) to you regarding pursuing your career choice? Do you think there are barriers to women with careers in STEM? Why? Do you think this is changing? Why?

Carina: My uncles are in construction and have built house for people in oil and gas and want me to meet all these people. They are very supportive and call me their 'retirement plan!' I'm definitely not letting them down.

Carina reveals that she is motivated to make her uncles proud and as they joke about her being their future security, she is interested in their external affirmation and understands that she has a responsibility to succeed and earn a good living.

Ellie: My mom went back to school when we were younger and became an educator. My dad is in computer technology. He didn't go to school but is like naturally intelligent. They always wanted me to do something lucrative. If you are going to get your fashion merchandising degree, you can find someone else to pay for it.'

Ellie discusses the role expectations of her parents that promote her behavior of pursuing a career that is in a lucrative field. She values her parents and their educational and intellectual abilities and seeks to be accepted.

Anisa: They are very supportive. Mom started me in the camps early and Dad is in computer science. Grades are important to the family, but there was a push to pursue a lucrative career. I can be like my brother too. He is at Ohio State and majoring in Mechanical Engineering.

Anisa reveals the push by her family to seek good grades and a lucrative career. She is determined to achieve the expectations of her family and is externally motivated to be like her brother.

Jasmine: I am the oldest child and only girl. In Hispanic culture, I should have been a boy as the eldest. But I'm doing what my dad is doing. And as it turned out, my brother was in culinary school - so, I'm like, see, I'm way more awesome.

In this particular comment, Jasmine reveals an expectation that she attributes to her Hispanic culture. This expectation was that the eldest should be a son, and a son should follow in the footsteps of his father. In her family's case, she is the oldest, but she is a girl. Yet she is externally motivated to step into her brother's expected role and make her family proud.

Gabriela: I think my parents are very proud of me, not because of specifically what I'm going to be doing, but just the fact that I'm pursuing something that I enjoy. And I have stressed to them that my brother is one of the biggest influences in my life, just because he's been the person who said take this, what can you use with this plate and silverware... he'd come up with something I wouldn't even think about.

Gabriela mentions a similar, external motivation to receive the affirmation of her family. Yet, in her statement, she also reveals a more complex motivation source leading to internal self-concept-based motivation.

In this section, we can see how some students are guided in their behavior and motivation in ways that satisfy external reference groups. Although students had the opportunity to discuss external motivating forces such as peers and faculty, they did not respond to being influenced by others as much as they did by their families. Families proved to be a noteworthy external reference group from which students sought affirmation and felt a responsibility to fulfill expectations.

\section{Internal self-concept source of motivation}

The following table (Table 4) presents a summary of the coded subthemes within the theme of internal selfconcept of motivation.

Response highlights from question set \#3

Describe yourself as a student. What was your original declared major? What is your major now? What are your best subjects? Why? What are your least favorite subjects? Why?

Table 4 Emergent themes related to internal self-concept of motivation

\begin{tabular}{lll}
\hline Construct & Theory-driven codes & $\begin{array}{l}\text { Interview emergent } \\
\text { subthemes }\end{array}$ \\
\hline $\begin{array}{l}\text { Internal } \\
\text { self-concept } \\
\text { motivation }\end{array}$ & $\begin{array}{l}\text { Individual is primarily } \\
\text { inner-directed. }\end{array}$ & $\begin{array}{l}\text { Individual feels strongly } \\
\text { about their independence } \\
\text { and power to choose what } \\
\text { they pursue. }\end{array}$ \\
& $\begin{array}{l}\text { The individual sets internal } \\
\text { standards that become the } \\
\text { basis for the ideal self. }\end{array}$ & $\begin{array}{l}\text { Decisions are consistent } \\
\text { with personal standards of } \\
\text { behavior. }\end{array}$ \\
& $\begin{array}{l}\text { The individual tends to } \\
\text { define fixed standards of } \\
\text { self-measurement and later } \\
\text { aims to achieve higher } \\
\text { levels of competency. }\end{array}$ & $\begin{array}{l}\text { Likes to do things that give } \\
\text { a sense of personal } \\
\text { achievement. }\end{array}$ \\
& $\begin{array}{l}\text { The motivating forces are } \\
\text { inner-driven and motivated } \\
\text { by their self-concept. }\end{array}$ & $\begin{array}{l}\text { Decision making is driven } \\
\text { by personally set standards } \\
\text { for self. }\end{array}$ \\
\hline
\end{tabular}


Question set three probed students' internal selfconcept and explored the challenges and successes of their academic pursuits. The following comments are self-explanatory and are not individually analyzed. Students discussed some of their insecurities as women in a male dominated environment, the perception that men would or should know more than women in STEM classes. Some suggested that large classes and the inattention of their lecturer or the intimidation of such an environment were not conducive to their academic success. Some suggested that smaller class size helps to engage students and relieves feelings of being lost or insignificant. Finally, several discussed the importance and need for supplemental academic support or dedicated learning peers and caring professors.

Ellie: I took three math classes and dropped one. It was college algebra and a huge freshman lecture class. You could tell the lecturer was an older lecturer. I enjoyed my statistics class, as it was smaller. I feel like it would be good if supplemental instruction went along with math classes. I know people who have classes where all they do is take tests but I thinking having to practice is good. Forced practice is good.

Alicia: So far, classes are challenging. I don't struggle but I have to work hard to understand. Like I just learned the universal [coefficient] theorem and how it connects to my research project. Once I understand and can apply it, then I get it. I work twice as hard [as others] to understand, but once I get it then I really see the connection and it's much easier for me. I have to see how it's applied in a conceptual way for me to get it.

Carina: Honestly, I'm a little lazy, to be honest, especially when it doesn't really interest me. If it's something I have to do and I know I'm not going to like it. I guess I come to the point where, if it's too much material to where is overwhelming just to learn one simple thing, its just too much, and I get lazy about it and I don't even want to pursue reading it.

Jasmine: I prefer to work by myself, but I've noticed that the girls have started to gravitate to working together on group projects, but a lot of the guys are always asking for help whereas the girls try to figure it out on your own.

Gabriela: When you're one of like three girls, I feel like I have to be smarter because you are being looked down upon and judged.

Joslyn: I was weeded out of Aerospace engineering at (other University name) because I wasn't getting the grades I got in high school. I got a 74 on my $1^{\text {st }}$ test and so I fled. I didn't know about curves or that your grade on first test may not be your final grade. I didn't know to go talk to my teacher-or about rounding!

Christine: I'm independent and faster than the guys they would ask me for help sometimes, but I would be surprised because I thought they were supposed to be better than me.

\section{Emergent themes-interest development}

The following selected quotes from a longer transcript (using speaker pseudonyms) reveal the variety in responses regarding interest development. The following table (Table 5) presents a summary of the coded subthemes within the theme of interest development.

Response highlights from question set \#2

How long have you been interested in STEM? Was there a particular experience that you can remember that sparked that interest as a child, middle and high school student, and now college? If yes, can you please explain?

One of the underlying motives for this set of questions was to explore if students credited particular experiences with motivating or sustaining their interest in a STEM field of study. The following quotes reveal some of these memories:

Olivia: The first thing I wanted to be when I was younger was an astronaut. I'm from Galveston and they opened a new planetarium and my friends and I got to meet all these astronauts. I always really enjoyed my science classes. I don't feel like sociology or philosophy would spark my interest. It's like "hey here memorize

Table 5 Emergent themes related to interest development

\begin{tabular}{|c|c|c|}
\hline Construct & Theory-driven codes & $\begin{array}{l}\text { interview emergent } \\
\text { subthemes }\end{array}$ \\
\hline \multirow[t]{4}{*}{$\begin{array}{l}\text { Interest } \\
\text { development }\end{array}$} & $\begin{array}{l}\text { Interest can be seen as an } \\
\text { intrinsic force that } \\
\text { motivates the seeking of } \\
\text { knowledge for its own sake. }\end{array}$ & $\begin{array}{l}\text { Early experience or } \\
\text { interaction with a career } \\
\text { field leads to interest } \\
\text { development. }\end{array}$ \\
\hline & $\begin{array}{l}\text { Interest can be thought of } \\
\text { as a natural predisposition } \\
\text { to engage with particular } \\
\text { ideas, activities or physical } \\
\text { objects. }\end{array}$ & $\begin{array}{l}\text { Influence of a sibling's } \\
\text { participation in a science or } \\
\text { mathematics event as an } \\
\text { early interest trigger. }\end{array}$ \\
\hline & $\begin{array}{l}\text { Children have the ability to } \\
\text { sustain an interest in } \\
\text { conceptual domains when } \\
\text { exposed to particular }\end{array}$ & $\begin{array}{l}\text { Access to early experiences } \\
\text { with tools as both } \\
\text { developing interest and } \\
\text { motivation. }\end{array}$ \\
\hline & concepts in childhood. & $\begin{array}{l}\text { Access to a family member } \\
\text { in STEM or STEM education } \\
\text { has served as a motivating } \\
\text { role model. }\end{array}$ \\
\hline
\end{tabular}


Aristotle." I like hands on and doing things. Science does take memorization but it's more hands on."

Olivia describes her visit to a new planetarium when she was a student as influential.

Alicia: I have an older brother who was in a science fair and created an amusement park out of K'NEX and I thought it was so cool! The Ferris wheel moved. Also, I really loved Rollercoaster Tycoon. I spent hours designing. I knew I was an engineer right there.

Playing that I knew that I was going to be an engineer.

Alicia describes the influence of her brother's participation in a science fair as an early interest trigger.

Sarah: We did a lot of residential work growing up. At first I only watched and then I was allowed to wield tools. My parents remodeled the home and I was finally allowed to wield tools. It was like, "Look, I can make something out of this!"

Sarah credits her family's building construction business and access to early experiences with tools as empowering.

Gabriela: When I was little...we had a Synertek, the $3^{\text {rd }}$ Apple computer [and it was] always crashing - so I had to troubleshoot to fix it so could play the computer games (internet didn't work on it). Both my parents worked at Apple so I always had a computer... Dad would take apart a computer to show me the inside and teach me how to fix it. I was really young when I saw the inside of a computer - it looked like a little city!

Gabriela describes her early exposure to computers, problem solving, and her father's involvement with her as early influences to identify with STEM as well as her parents serving as role models.

Ellie: "[STEM] sparked my interest at a young age. My high school was in a great school district. They offered AP Bio, Anatomy, regular Bio, Chem. It confirmed that this is something that I wanted to be doing."

Ellie discusses her experiences in a STEM-focused high school as confirming of her field of study choice.

Joslyn: My Mom was a biology teacher - so my whole life was a science lesson! Like when I was 7 years old I learned about genetics from my mom because my older sister said I was adopted.

Joslyn notes that her mother, a science teacher, serves as a role model and learning support at home.
Analysis revealed that the majority of these students readily point to early experiences of hands-on learning with building kits or with real technologies such as computers. They reveal great joy when, for example, they describe their use of real building tools and how this transformed how they see and think of themselves. Many also identified an early STEM-career role model such as a family member or community hero. Some students also point to strong academic programs in their schools that welcomed girls and helped them become familiar with advanced science, technology, pre-engineering, and/or mathematics courses.

\section{Quantitative questionnaire data}

The raw questionnaire data was first reviewed to identify incomplete instruments and duplicate entries. In the case of duplicate entries, student's most recent entry was retained for the analysis and the older entry was removed from the data set. Thus, an initial set of 54 questionnaire responses resulted in 48 usable, nonduplicated response sets that were used in this analysis. One participant did not choose to answer all of the questions, and thus, some question results are based upon 47 students. In order to examine in what ways the Latina and African-American students differed in their responses versus the White students, the questionnaire responses were sorted by self-reported ethnicity. As the population, especially when divided into minority and White student groups, was too small for meaningful results from factor analysis (Thompson 2004; Tabachnick and Fidell 2013), $t$ tests were run for the Likert scale responses, which are presented along with their effect sizes, Cohen's $d$ (Grissom and Kim 2005), and N-1 two proportion tests were used for binary (yes/no, e.g.) questions to analyze the sorted data for potential differences. Binary questions were also evaluated with chi-square tests when frequency data supported this kind of test (Pett 1997). Further, groupings of questions on a common theme using Likert scale responses were evaluated for their inter-question reliability with Cronbach's $\alpha$ (Cronbach 1951), which was calculated for the total sample as well as the two student groups. These question groupings were further evaluated with a correlation matrix using Spearman's correlation (Tabachnick and Fidell 2013). Because each question group was focused on a different topic (reasons for choice, self-efficacy, etc.), it was expected that inter-item reliability across a larger group of questions and most inter-item correlations would be low. Further, multiple Likert scales had been used for different question groups (Edzie 2014). These reasons were combined for the rationale to examine the survey by common themes. The correcting significance levels for type I error using a Bonferroni correction (Myers and Well 1995) are also discussed for 
each question grouping. The mean responses of student groups are graphed for each question group and reported in tabular form alongside standard deviation and 95\% confidence intervals.

Of the questionnaire respondents $(N=48), 54 \%$ identified themselves as White, non-Hispanic, and the rest $(46 \%)$ as a minority or multi-racial; therefore, the student population in this survey study allowed for comparison between different cultural groups to examine differences and similarities (Table 6).

\section{Interest development and choosing to major in STEM} Question: What is the PRIMARY factor that influenced you to enroll in a collegiate science, technology, engineering, or mathematics (STEM) major?

One question in the instrument asked students to identify the primary factor that influenced them to enroll in their current STEM major. The results from this study are presented in Fig. 1 broken down by student's reported ethnicity. For simplification, data results are summarized under two group headings: White and minority students. The top two reasons provided by both the White and minority students, were "I am good at math and science" and "I wanted career options". These two reasons relate to ideas of internal self-concept and instrumental or extrinsic process, respectively, as defined for the MSI scales (Barbuto and Scholl 1998). When compared to another study (Edzie 2014), these two reasons were also prominent. The importance of career options and being good at math and science were in the reverse order for Edzie (2014) than for students in this study. The white students, more often than the minority students, reported wanting career options as their primary factor by almost 20 percentage points (62 and 43\%, respectively). Despite this large difference in percentage, the results are not statistically significant at a 95\% confidence level (one tailed N-1 two proportion test, $p=0.103$ ), likely due to the small sample size that resulted from dividing the respondents by ethnicity. Minority students still cited career options more commonly than any other choice (43\%), but the response

Table 6 Student demographics

\begin{tabular}{lll}
\hline Race & Frequency $(N=48)$ & Percentage (\%) \\
White (non-Hispanic) & 26 & 54 \\
Hispanic & 17 & 35 \\
African American & 4 & 8 \\
Multi-racial & 0 & 0 \\
Asian & 2 & 4 \\
Classification & Frequency $(N=48)$ & Percentage (\%) \\
Graduate & 4 & 8 \\
Senior & 19 & 40 \\
Junior & 17 & 35 \\
Sophomore & 7 & 15 \\
Freshman & 1 & 2 \\
\hline
\end{tabular}

was very close to their citing being good at math and science $(38 \%)$ as their primary factor for majoring in STEM. The remaining six factors were cited infrequently (by less than $10 \%$ of the respondents) as being their primary motivating factor.

Question: What factors have influenced you to enroll in a collegiate science, technology, engineering, or mathematics (STEM) major? (Choose all that apply.)

This study also included a question requesting the students to select all of the factors that influenced their decision to enroll in a STEM major (Fig. 2). Thus, Fig. 2 shows the relative influence of the pre-collegiate experiences represented by the six low ranking factors from Fig. 1. For instance, students reported participation in math and science focused extra-curricular activities as an influence in their decision to persist for a third (33\%) of the minority students and a quarter (27\%) of the White students. Students were also influenced by having a parent working in a STEM field, which is often cited in literature as a factor in female STEM persistence (Gabay-Egozi, Shavit and Yaish 2015). Forty percent of the overall student response cited this factor as one of their influences. Minority students cited this factor fewer times than White students (38 and 42\%, respectively), but the responses were similar. Figure 2 also closes the gap on the influence of wanting career options between the student groups with minority and White students strongly indicating this factor influenced their STEM enrollment (86 and 88\%, respectively). With the exception of "My school counselor encouraged me" (one tailed N-1 two proportion test, $p=0.031$ with the White students more likely to cite this factor), none of the differences between the responses of these two student groups in Fig. 2 were statistically significant. These various pre-collegiate experiences could relate to different MSI subscales depending on how these factors influenced the individual student. For instance, a parent working in the STEM field could result in an external selfconcept motivation as the student seeks approval from that parent; an instrumental/extrinsic process motivation in pursuit of a career with a high salary similar to their parent's career or internal self-concept as the student views their choice as a result of their high standards modeled upon their parent(s).

Question: Why did you choose your major? Indicate the extent to which you feel the following statements are true of your decision to major in a STEM field.

Table 7 presents the inter-item reliability statistics, Cronbach's $\alpha$, for this set of questions about why students chose to major in a STEM field. A Cronbach's $\alpha$ of 0.7 or higher is considered to show some degree of inter-item agreement, and as the value increases, it 


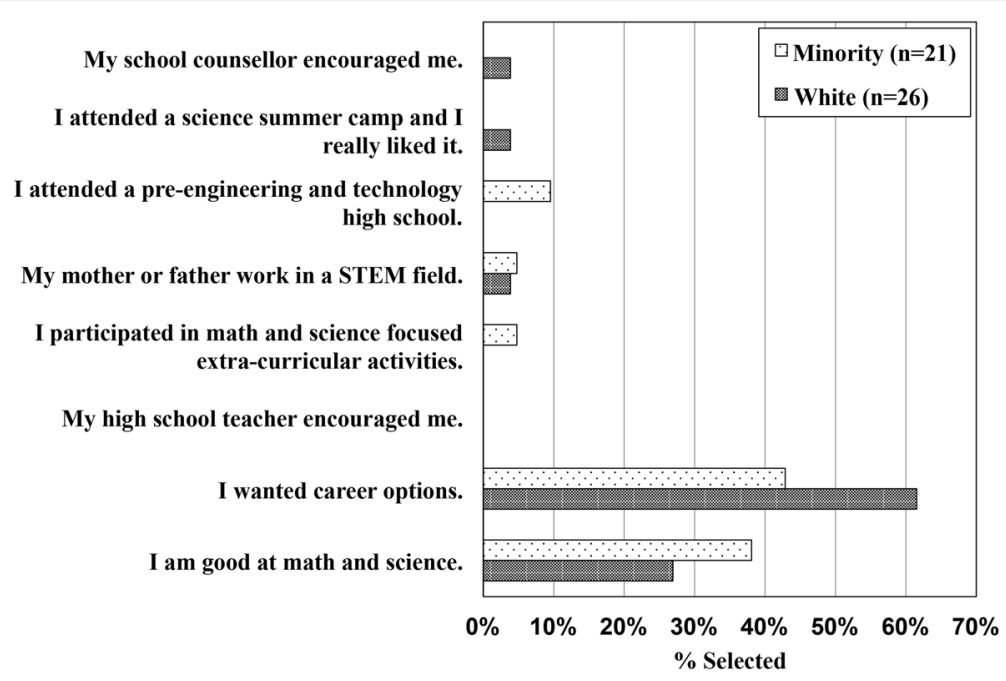

Fig. 1 Primary factor for selecting a STEM major

indicates an increasing inter-item agreement (Tabachnick and Fidell 2013). For this question set, $\alpha$ is only above the 0.7 threshold for White students but very near the threshold for minority students or when all students are considered together. The moderate value of $\alpha$ in these responses indicates that this group of statements can reasonably be analyzed with a composite score to examine students' overall tendency to agree with this series of statements for why they chose their major. The authors are specifically interested in which reasons the students cited for choosing their major and, therefore, also examined response differences at the individual statement level as well as the composite level. Table 8 further presents the correlations between the items in this question grouping. Correlations for the minority students are reported below the diagonal and correlations for White students are above the diagonal. For the group of questions to be expected to reasonable correlated, it would be expected that all of the reported correlations would be at 0.3 or higher. As many of the correlation values are below this threshold, it can be seen that these questions about why students chose their major typically do not measure the same item

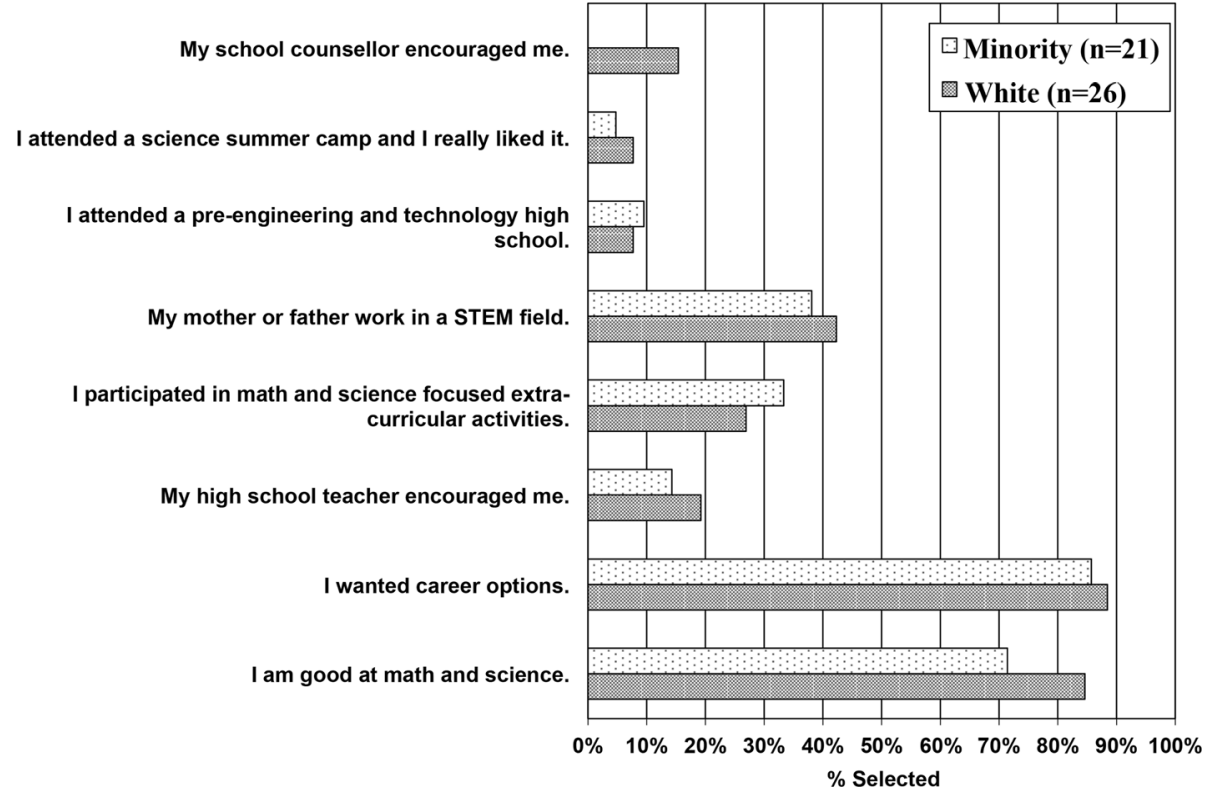

Fig. 2 All factors in selecting a STEM major 
Table 7 Reliability statistics for "Why did you choose your major?"

\begin{tabular}{cccc}
\hline & All students & Minority students & White students \\
\hline Cronbach's a & 0.67 & 0.62 & 0.71 \\
\hline
\end{tabular}

in several ways but instead are measuring different, unrelated reasons the students have identified as being true of their choices. As these questions are not highly related, the individual statements were evaluated against a significance level of 0.05 , rather than a corrected significance level of 0.0045 that was used for the composite scores to account for type I error on related items. Overall, the two student groups responded to the statements about why they chose their major at a similar rate $(M=6.07$ and $6.01, \mathrm{SD}=$ 0.60 and 0.62 , and $95 \%$ CI [4.91, 7.24] and [4.79, 7.23] for minority and White students, respectively). The difference between these composite scores is not statistically significant. The real interest in this series of questions, however, is in what, if any, differences were there in the statement-level responses. Therefore, Fig. 3 presents the average student responses by student group are presented for the individual statements alongside the composite scores for each group. A striking result from Fig. 3 is that minority students ranked their personal interest in their field of study as the lowest ranking factor (5.38) in choosing their major. This factor was ranked fairly high by the White students in the study (6.27) and is the only statistically significant difference between the two groups for this grouping of statements, $t(28)=-1.77$, $p=0.044$, from a one-tailed $t$ test with White students being more likely to cite their personal interest in their field of study as a factor in choosing their major. This statement also has a medium effect size $(d=0.59)$ whereas the other reasons for choosing a STEM major had small effect sizes, indicating that the student responses to this statement did differ a noticeable amount. While most of the minority students are not saying that they dislike their field of study, $24 \%$ of the minority students indicated some degree of that statement not true of them (less than neutral). For comparison, none of the White students indicated that the statement was not true of them to any degree. Instead, the top three factors selected by minority students were all career related $(6=$ True of $\mathrm{Me}$ ): Career Opportunities (6.52), Job Security (6.30), and Salary Opportunities (6.29). These three factors were all of the instrumental motivation factors listed in this question grouping. Also tied for third place ranking by minority students is the enjoyment of science, an intrinsic process motivation, as a reason for choosing their major (6.29). This factor, along with the self-efficacy statement of being good at math and science in high school (6.05), an internal self-concept motivation factor, points to pre-collegiate preparation that encouraged these minority women to pursue STEM majors. The top three factors selected by the White students in this study showed them also to be highly motivated by career-related (instrumental motivation) factors: Career Opportunities (6.38), Job Security (6.38), and Salary Opportunities (6.31).

\section{Sources of motivation and persistence Question: Indicate the extent to which you feel the fol- lowing statements are true of your motivations to pursue your major.}

Similar to the results seen in Table 7 , the reliability statistics presented in Table 9 show values of Cronbach's $\alpha$ that are very near the threshold of 0.7 and thus this subgroup of questions are of interest to examine additionally at the composite level. A moderate inter-item reliability indicates that there is some variance amongst the responses to the items in this group of questions about what factors motivate students to pursue their majors. The higher $\alpha$ for the minority students versus the White students suggests a trend that the minority students had more similar responses to all of the sources of motivation than the white students. While the composite score for each student group was examined to look for overall differences in the level of motivation to pursue a STEM major, the individual items were also explored to see if any of the factors of motivation differed between the student groups. Table 10, which presents the correlation matrix for this group of statements, further supports this analysis approach as the correlation is not consistently above 0.3 . As the correlations within this grouping are only sporadically above 0.3 , some of these items relating to what different factors motivated the students to pursue their major are likely independent and can therefore be evaluated with a significance level of 0.05 rather than the corrected significance level of 0.008 to control for type I error when comparing the composite scores. Figure 4 presents the composite scores of the two student groups' responses as well as the average responses on a 7-point Likert scale to a series of statements about what factors motivate them to persist in their STEM major. For most of these questions, the minority and White students had very similar responses, and the overall level of motivation to pursue their STEM majors as measured by the composite scores for these groups were nearly identical $(M=5.58$ and $5.58, \mathrm{SD}=$ 1.06 and 0.81 , and $95 \% C I[3.49,7.66]$ and $[3.99,7.16]$ for minority and White students, respectively). Further, the small difference between these composite scores was not statistically significant. The overall top two motivating factors were students' personal drive and desire to 
Table 8 Correlations for responses to "Why did you choose your major?"

\begin{tabular}{|c|c|c|c|c|c|c|c|c|c|c|c|}
\hline & 1 & 2 & 3 & 4 & 5 & 6 & 7 & 8 & 9 & 10 & 11 \\
\hline 1. I chose my major because I enjoy math. & - & 0.387 & -0.19 & 0.22 & 0.11 & - & -0.25 & $0.55^{* *}$ & 0.34 & $0.44^{*}$ & 0.25 \\
\hline 2. I chose my major because I enjoy science. & 0.19 & - & 0.12 & 0.21 & 0.15 & -0.18 & 0.16 & 0.25 & 0.3 & 0.17 & 0.14 \\
\hline $\begin{array}{l}\text { I chose my major because I see great career opportunities } \\
n \text { the STEM field. }\end{array}$ & 0.40 & 0.094 & - & $0.50^{*}$ & $0.503^{* *}$ & $0.51^{* *}$ & $0.51^{* *}$ & 0.27 & 0.19 & 0.21 & 0.37 \\
\hline 4. I chose my major because I want to help others. & 0.11 & -0.402 & $0.59^{* *}$ & - & 0.40 & 0.30 & 0.13 & 0.23 & 0.15 & 0.17 & 0.35 \\
\hline $\begin{array}{l}\text { 5. I chose my major because I think there are great salary } \\
\text { opportunities in the STEM }\end{array}$ & -0.10 & 0.098 & $0.43^{*}$ & 0.27 & - & $0.45^{*}$ & 0.26 & 0.11 & 0.17 & 0.26 & $0.55^{* *}$ \\
\hline $\begin{array}{l}\text { I chose my major because I appreciate the job security that } \\
\text { TEM career fields offer. }\end{array}$ & 0.20 & -0.277 & $0.56^{*}$ & $0.55^{*}$ & 0.37 & - & 0.19 & 0.14 & 0.28 & 0.20 & 0.15 \\
\hline 7. I chose my major because my major field interests me. & 0.11 & 0.183 & $0.44^{*}$ & 0.28 & 0.24 & $0.56^{*}$ & - & 0.22 & 0.19 & 0.29 & $0.47^{*}$ \\
\hline $\begin{array}{l}\text { 8. I chose my major because I was good at math and science in } \\
\text { high school }\end{array}$ & 0.29 & -0.4 & 0.23 & 0.25 & 0.36 & $0.56^{*}$ & 0.16 & - & 0.32 & $0.45^{*}$ & $0.46^{*}$ \\
\hline 9. I chose my major because I feel I will be capable in this field. & 0.23 & 0.217 & 0.41 & 0.24 & 0.18 & $0.62^{* *}$ & $0.90^{* *}$ & 0.12 & - & $0.41^{*}$ & 0.13 \\
\hline $\begin{array}{l}\text { 10. I chose my major because I am academically prepared to } \\
\text { succeed. }\end{array}$ & 0.32 & 0.022 & -0.23 & -0.33 & -0.171 & 0.25 & 0.23 & 0.29 & 0.39 & - & $0.40^{*}$ \\
\hline 11. I chose my major because I want to pursue this major. & 0.33 & 0.323 & 0.23 & 0.24 & -0.132 & 0.41 & $0.55^{* *}$ & -0.08 & $0.72^{* *}$ & 0.37 & - \\
\hline
\end{tabular}

Notes: Correlations for White students $(n=26)$ are presented above the diagonal, and correlations for minority students $(n=22)$ are presented below the diagonal. *Means correlation is significant to the 0.05 level, and ${ }^{* *}$ means correlation is significant to the 0.01 level

pursue their STEM majors with overall responses greater than 6, True of Me (6.49 and 6.11, respectively). These factors are internal self-concept motivations that have similar ratings to the instrumental motivation factors in Fig. 3. The students in this study also reported the challenging nature of their STEM fields, an internal selfconcept factor, to be a motivation for persistence at a high level (5.91 overall). The family support factor in student motivation was the only individual item with a statistically significant difference between the two student groups, $t(44)=1.81, p=0.038$, with the minority students responding with higher identification with the statement than for White students. This motivation factor was the only external self-concept motivation factor

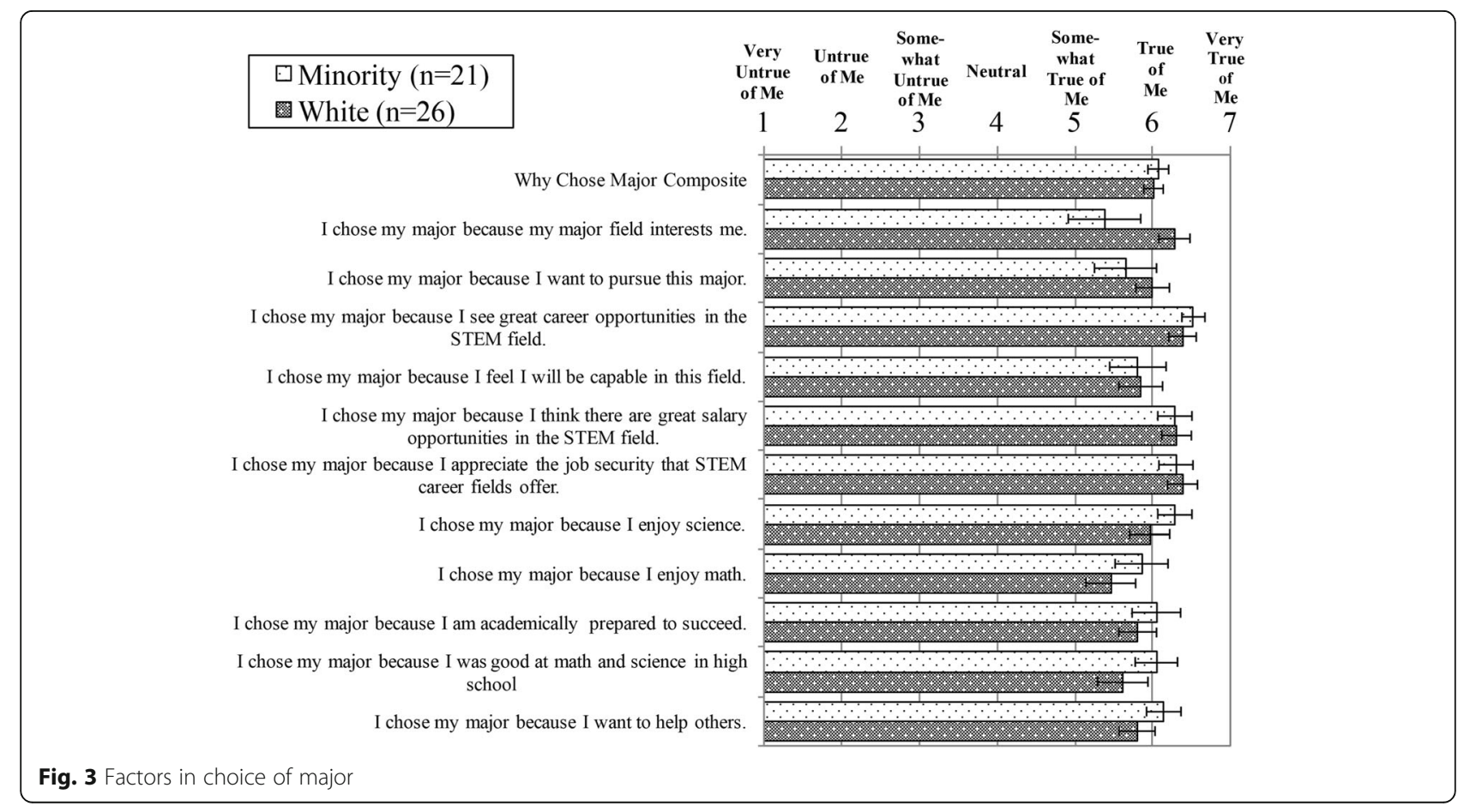


Table 9 Reliability statistics for motivations to pursue STEM majors

\begin{tabular}{cccc}
\hline & All students & Minority students & White students \\
\hline Cronbach's $a$ & 0.66 & 0.70 & 0.62 \\
\hline
\end{tabular}

that ranked highly in this grouping. The question about family influences on a students' motivation pursue their major has a medium effect size $(d=0.52)$. All other effect sizes for this group of questions are small. All of the other highly ranked factors in Fig. 4 are internal selfconcept motivations. The other responses did not have a statistically significant difference in response between the two groups. As the other factors were ranked in the same order of importance for the two groups excepting that family support was the third highest ranked motivating factor for the minority students versus the challenging nature of the major for the white students, the lack of statistical significance for the other responses is not surprising.

Questions: Do you currently plan on graduating with a degree in your major? Do you intend on pursuing graduate school?

The questions of whether students intend to graduate in their current STEM major and to pursue graduate degrees had three options for their answers: yes, unsure, or no. These questions were envisioned as a gauge of students' stated motivation to persist in their chosen STEM fields. A limitation to this question series is that the question about graduate school did not specify that the graduate degree would be in their current STEM field, another STEM field, or a non-STEM field. For instance, one student indicated that she did not intend to graduate with a degree in her current STEM major but that she did intend to pursue a graduate degree. As a result of the question structure, the authors are unable to determine if this student wishes to change fields within STEM or plans to leave STEM. Beyond this one student intending to change majors, there was one student who indicated she had been pursuing her current STEM major for less than a year and was unsure of whether she would graduate with a degree in her current major. All other students indicated they intend to graduate in their current STEM major. There was no statistically significant difference between White and minority students in their intent to graduate in their current major or in their intent to attend graduate school. As the students' response to whether they will graduate with a degree in their major was so heavily weighted in affirmative responses, the frequency of students replying "no" or "unsure" was too low $(<5)$ to be able to run a chi-square analysis for the question. The question asking whether students intended to pursue graduate school had one category with a low frequency, but it met the requirements to run a chi-square test (Pett 1997). The result of this test was a statistically insignificant low chi-square value, $c^{2}(2, N=48)=0.72, p$ $=0.70$. As such, a null hypothesis of independence between ethnicity and intent to pursue graduate school cannot be rejected.

Question: Indicate how important you believe each factor to be in influencing your decision to persist in a STEM field of study at Texas State University:

Table 11 presents the inter-item reliability measures, Cronbach's $\alpha$, for this group of questions about students' decision to persist in their STEM majors. Only the grouping of minority students had an $\alpha$ above the 0.7 threshold, although the other student groups are near this threshold. This result indicates that the minority students tended to respond to the questions with less variance than the White students. As the $\alpha$ is not especially high for either of the student groups, this result means that there is still variance amongst the answers although there is enough consistency to report the composite scores. The correlation between the different factors in this grouping are presented in Table 12. There are only sporadic correlations of 0.3 or above in this matrix; therefore, these measures fail to show correlation and consistency amongst the items in this grouping. As these questions appear to have some independence amongst a common theme, they were analyzed individually versus a standard significance of 0.05

Table 10 Correlations for motivations to pursue STEM majors

\begin{tabular}{|c|c|c|c|c|c|c|}
\hline Factor & 1 & 2 & 3 & 4 & 5 & 6 \\
\hline 1. I find motivation to pursue my major from the faculty in my major. & - & 0.31 & 0.27 & 0.34 & 0.06 & -0.08 \\
\hline 2. I find motivation to pursue my major from my parents and/or family members. & 0.34 & - & 0.22 & 0.37 & 0.13 & 0.10 \\
\hline 3. I find motivation to pursue my major from the challenging nature of my major. & 0.32 & -0.083 & - & 0.35 & $0.47^{*}$ & $0.53^{* *}$ \\
\hline 4. I find motivation to pursue my major from my friends & $0.49^{*}$ & 0.36 & 0.34 & - & 0.2 & 0.35 \\
\hline 5. I find motivation to pursue my major from my personal drive/ambition. & 0.06 & 0.34 & $0.57^{* *}$ & 0.27 & - & $0.58^{* *}$ \\
\hline 6. I find motivation to pursue my major from my desire to pursue my major. & 0.05 & 0.27 & $0.50^{*}$ & 0.32 & $0.93^{* *}$ & - \\
\hline
\end{tabular}

Notes: Correlations for White students $(n=26)$ are presented above the diagonal, and correlations for minority students $(n=21)$ are presented below the diagonal. *Means correlation is significant to the 0.05 level, and ${ }^{* *}$ means correlation is significant to the 0.01 level 


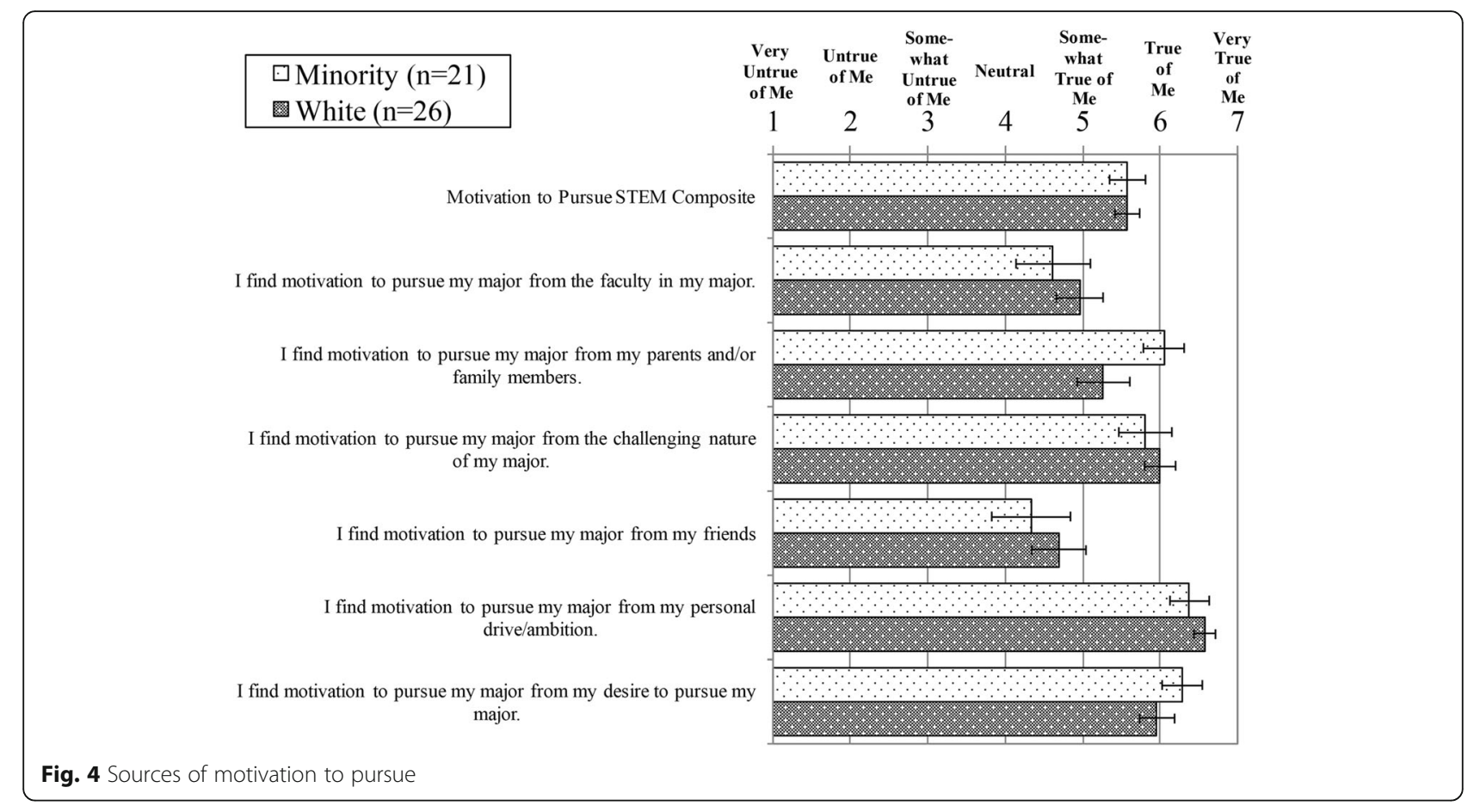

as well as analyzed as a composite score. The $t$ test for the minority and white student groups' composite scores were examined with a corrected significance of 0.006 to account for type I error from analyzing related items. Regardless of significance measure used, there are no statistically significant differences between minority and White students in either the composite score or the series of statements about factors that influenced their decision to persist, as shown in Fig. 5. These groups had similar composite scores $(M=2.41$ and $2.38, \mathrm{SD}=0.40$ and 0.34 , and $95 \% C I[1.62,3.20]$ and $[1.70,3.05]$ for minority and White students, respectively), which suggests that the two groups has similar levels of motivation to persist in their STEM majors. By examining the individual item level as well, the authors sought to identify trends in the sources of student motivation. Both groups, for instance, had much higher responses towards the influence of their personal commitment to their goals (educational and career) than any lingering effects of their ACT/SAT scores or high school performance as shown in Fig. 5. Every student had an above neutral response to the factor of commitment to goals, an internal self-concept motivation factor, with all of the White students and all but two (91\%) of the minority students indicated it was

Table 11 Reliability statistics for motivations to persist

\begin{tabular}{cccc}
\hline & All students & Minority students & White students \\
\hline Cronbach's a & 0.68 & 0.79 & 0.65 \\
\hline
\end{tabular}

"Very Important". Those two students ranked that factor as "Somewhat Important", so that the average rating for this factor was 2.91 out of 3 for minority students and 3 out of 3 for White students. No other factors in this group of statements had this level of agreement amongst the participants, as all others had at least one student ranking the factor as "Not Important". This particular factor also has a medium effect size $(d=$ 0.67), which indicates that the response distributions are noticeably different. As all the White students gave the same response, there is no variation in that group of data for this question, which would certainly be noticeable versus the minority students' response which did have some variation. The other factors after commitment to goals rounding out the top four factors for minority students (with $90 \%$ or more participants ranking the factor above neutral) are confidence in their quantitative skills (95\% above neutral, 2.77 average rating), family support $(91 \%, 2.73)$, and financial needs $(91 \%, 2.68)$. While the White students have the same top four factors by average rating (commitment to goals $=3.00$, confidence in quantitative skills $=2.65$, financial needs $=2.58$, and family support $=2.50$ ), the top four factors by above neutral responses trade family support for study skills. These top factors represent a mixture of internal self-concept (confidence in quantitative skills and study skills), eternal self-concept (family support), and instrumental (financial needs) motivations. As in previous figures, family support is the only external self-concept motivation that ranks 
Table 12 Correlations for motivations to persist

\begin{tabular}{|c|c|c|c|c|c|c|c|c|c|}
\hline Factors & 1 & 2 & 3 & 4 & 5 & 6 & 7 & 8 & 9 \\
\hline 1. My high school academic achievement was important in my decision to persist. & - & $0.47^{*}$ & 0.33 & - & 0.37 & 0.11 & -0.10 & 0.12 & $0.43^{*}$ \\
\hline 2. My SAT/ACT scores were important in my decision to persist. & $0.47^{*}$ & - & -0.18 & - & 0.34 & 0.36 & -0.08 & 0.13 & 0.38 \\
\hline 3. My study habits are important in my decision to persist. & $0.48^{*}$ & 0.21 & - & - & 0.18 & 0.09 & 0.07 & 0.01 & 0.09 \\
\hline $\begin{array}{l}\text { 4. My commitment to career and educational goals is important in my decision to } \\
\text { persist. }\end{array}$ & $0.47^{*}$ & 0.07 & 0.22 & - & - & - & - & - & - \\
\hline $\begin{array}{l}\text { 5. My confidence in quantitative skills (computer skills, mathematical ability, } \\
\text { creativity) are important in my decision to persist. }\end{array}$ & 0.17 & -0.10 & 0.27 & 0.241 & - & 0.34 & 0.04 & 0.38 & -0.05 \\
\hline $\begin{array}{l}\text { 6. My commitment to this University (Texas State University) is important in my } \\
\text { decision to persist. }\end{array}$ & 0.32 & 0.27 & 0.38 & $0.454^{*}$ & 0.42 & - & 0.38 & 0.33 & 0.31 \\
\hline 7. My financial needs are important in my decision to persist. & -0.24 & 0.13 & -0.03 & 0.17 & -0.01 & -0.22 & - & 0.10 & 0.31 \\
\hline 8. Having family support is important in my decision to persist. & 0.33 & 0.19 & 0.25 & 0.297 & 0.41 & $.43^{*}$ & 0.25 & - & 0.09 \\
\hline 9. Social engagement at the university is important in my decision to persist. & 0.21 & $0.45^{*}$ & -0.10 & 0.345 & 0.23 & $0.45^{*}$ & 0.16 & 0.38 & - \\
\hline
\end{tabular}

Notes: Correlations for White students $(n=26)$ are presented above the diagonal, and correlations for minority students $(n=22)$ are presented below the diagonal. *Means correlation is significant to the 0.05 level. All White students chose the same response to factor 4 , which resulted in a null correlation

highly and often trends higher for the minority students even when the difference between the groups is not statistically significant.

Questions: Is it important to you to have a career that positively impacts society? Do grades matter to you? Do you feel grades matter more to your male peers than they do to you?

Figure 6 presents the results from three yes/no questions in the questionnaire regarding the importance of altruism, grades, and perceptions of their male peers. The graph shows the percentage of respondents replying "yes" to each question. The first question, "Is it important to you to have a career that positively impacts society?" echoes the importance of altruism asked as a part of Fig. 3, "I chose my major because I want to help others." For both measures of student altruism, the students in this study indicate high identification with the concept; a factor in internal self-concept motivation as well as goal internalization motivation. The students in

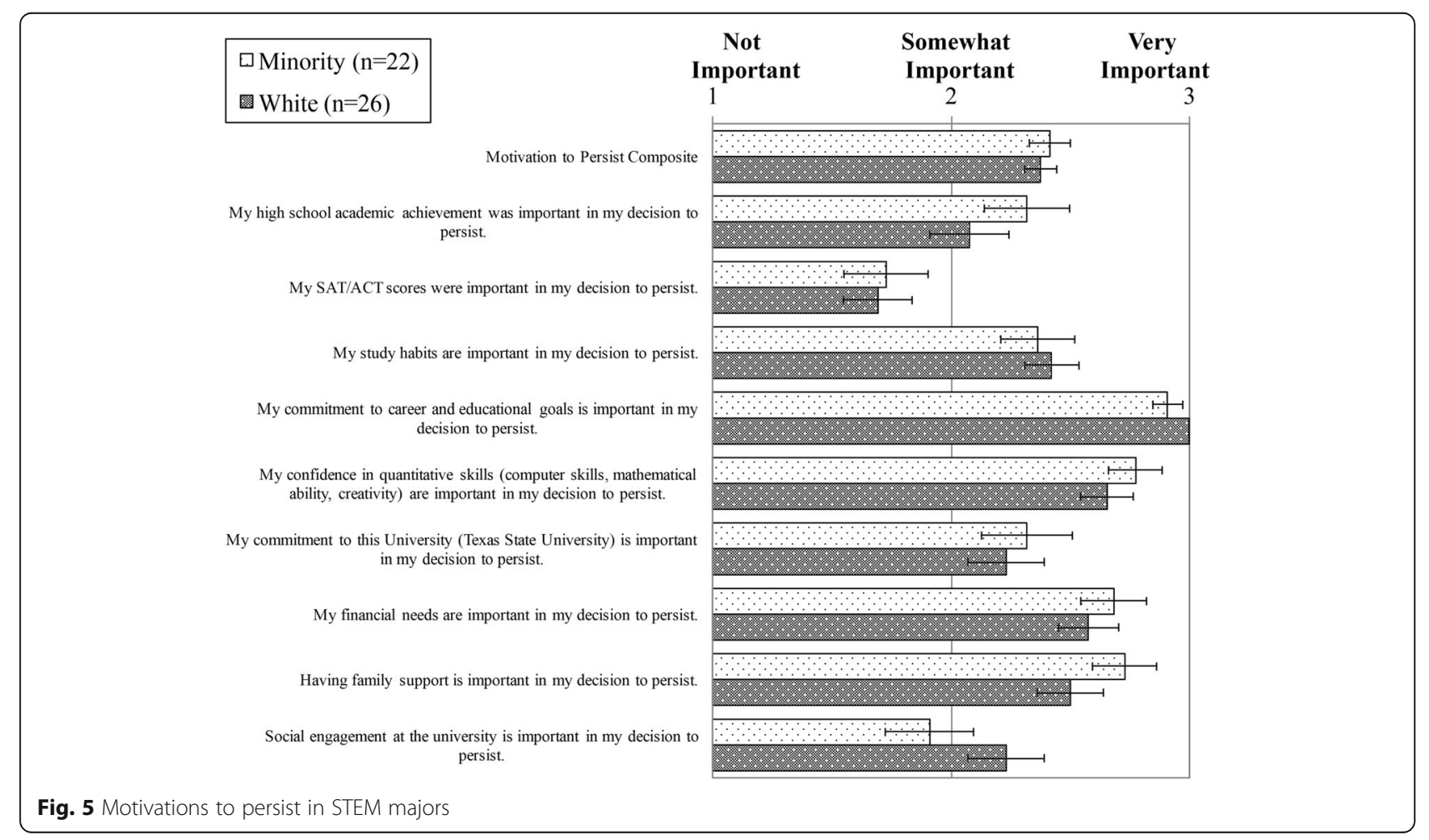


this study found grades to be a highly influential factor, with $84 \%$ overall (including both white and minority) agreement to the question, "Do grades matter to you?" a factor related to internal self-concept motivation. Of particular note is that the minority students in this study felt far more strongly (30\%) that grades mattered more to their male peers than to them versus the White students in this study (4\%). This third question is the only one of this grouping with a statistically significant difference in response between the student groups (one-tailed N-1 two proportion test, $p=0.004$ with the minority students more likely to agree). These three questions failed the data frequency assumptions necessary to run a chi-square test. The student response, as graphed in Fig. 6, were either predominately positive or negative. As such, the minimum data frequency of five responses was not meet $25-50 \%$ of the time for these tables and, therefore, the chi-squared test could not be calculated (Pett 1997).

\section{Motivated strategies for learning questionnaire Question: Indicate the extent to which you agree or disagree with each of the following:}

Figure 7 presents the students' performance motivation self-efficacy using a subsection, "self-efficacy for learning and performance motivation" of the MSLQ (Pintrich et al. 1991). This subsection includes a number of areas related to their STEM majors such as: understanding of basic concepts, mastery of skills, expectations of doing well and understanding of difficult concepts. The inter-item reliability presented in Table 13 indicates that the items within this set of questions ask similar things, with all student groups having $\alpha$ greater than 0.8. Table 14 shows that there are many correlations at or above the 0.3 level. As this question grouping is a subset of the MSLQ looking at students' performance motivation self-efficacy, high Cronbach's $\alpha$ results and widespread correlations are not surprising. For most of these questions, the minority and White students had very similar responses, and the composite scores for these groups were nearly the same $(M=5.84$ and 5.80 , $\mathrm{SD}=0.72$ and 0.77 , and $95 \% C I[4.43,7.25]$ and [4.29, 7.31] for minority and White students, respectively. This similarity in composite score suggests that the two groups of predominately juniors and seniors majoring in STEM are emerging from their courses of study with very similar levels of self-efficacy for their learning motivation. When controlling for type I error, the corrected significant level would be 0.006 , and the small difference between the composite score was not statistically significant. When examining the individual items to try to explore the elements of the students' self-efficacy, the student groups' responses differ the most in two areas: understanding of basic concepts and expectation of an excellent GPA. For both of these instances, the minority students had lower self-efficacy than the white student; however, none of the differences in response between the two groups was statistically significant to the $95 \%$ confidence level. The student responses to understanding the basic concepts does have a medium effect size $(d=0.46)$. A medium effect size (Grissom and Kim 2005) indicates that these two groups have noticeable difference between the groups. The effect size between the groups for expectation of excellent GPA is only small $(d=0.23)$. Overall, these self-efficacy measures yielded fairly consistent results across the factors, as evidenced by the high Cronbach's $\alpha$ results and relate to internal self-concept motivation factors.

\section{Discussion}

This study was motivated by institution's collective interest to better understand the factors that successful female students attribute to motivating their sustained interest and achievement in STEM academic fields of study. The study was conducted at a Hispanic-Serving Institution including a sample of 47 women successfully on track to completing their STEM degrees. The questionnaire data presented in the prior section reveal the results and the supporting statistical analysis. Unfortunately, the non-normality of the questionnaire data for

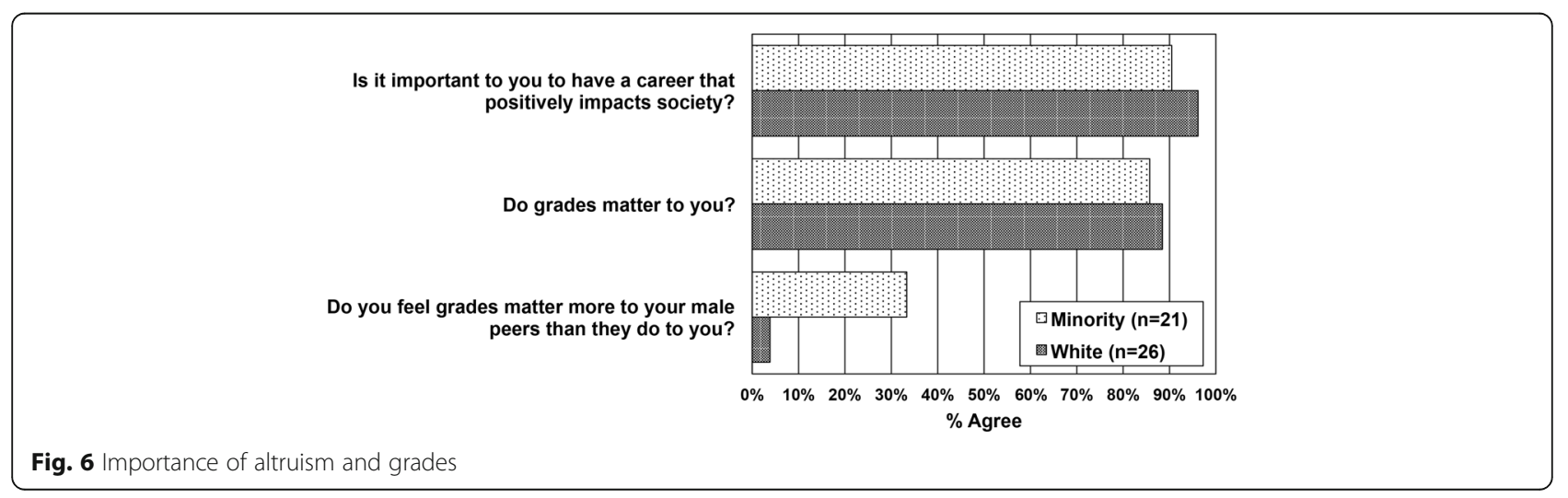




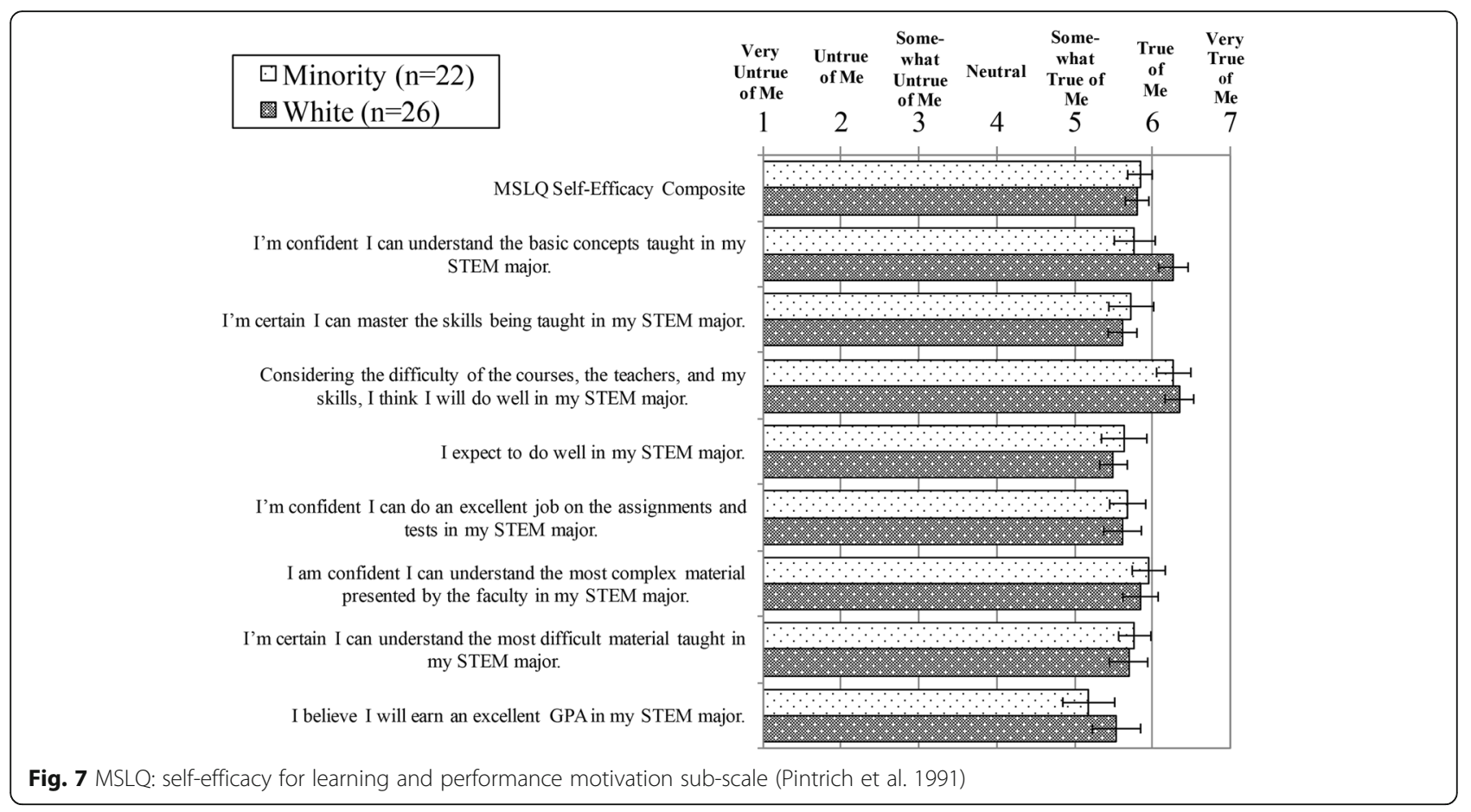

the minority and majority student groups may imply that $t$ tests are not sufficiently sensitive to detect differences between groups. The Mann-Whitney $U$ test may prove to be a more robust analysis in future review (Pett 1997). Nevertheless, by triangulating these findings with qualitative responses and further exploration of factors displaying a medium effect size (as measured by Cohen's $d$ of approximately 0.5 ), there is an indication of a visible difference between certain group distributions. For instance, there is a medium effect size for minority students to be more likely to attribute one source of motivation to pursue a STEM major deriving from a parent or family member. White students are more likely (with a medium effect size), to cite personal interest as a reason for choosing their STEM major. Other factors with medium effect sizes showed White students to be more likely than minority students to identify their personal ambition as a motivation to persist and their selfconfidence in understanding basic concepts in STEM. As such, these trends indicate a stronger family influence for the minority students than the White students and a greater self-confidence in their academic ambitions for the White students than the minority students.

Table 13 Reliability statistics for MSLQ subsection on selfefficacy for learning and performance motivation

\begin{tabular}{cccc}
\hline & All students & Minority students & White students \\
\hline Cronbach's a & 0.84 & 0.82 & 0.86 \\
\hline
\end{tabular}

Interest factors attributed to influencing STEM enrollment Focus group discussions revealed a wide range of factors that students credit for leading them to enroll in STEM majors. The questions aligned to this topic probed students' perceptions of the impact of particular experiences that sparked interest in STEM academic studies and careers. In general, students highlighted early active experiences involving in-school and out-of-school as ones they felt sparked original interest, joy, and intrinsic process motivation. In the questionnaire portion of the study, however, only two factors emerged as the primary factors in their choice: career options and being good at math and science. Many of the lower-ranked primary factors in STEM enrollment from the questionnaire (Fig. 1) can easily lead to the students believing in their abilities in math and science or being aware of the career options available to them with a STEM major, such as attending a science summer camp or being encouraged by a high school teacher. Indeed, students cited these factors in the focus groups as sparking their interest in STEM. Many of these pre-collegiate experiences lend themselves to be grouped as intrinsic process motivation sources as they helped participants find the fun in the doing of STEM. The external motivation factor of family support was also cited many times be the students in the focus groups, and this family support took on many forms as it sparked and drew students' interest in STEM fields. For instance, from discussion in focus groups, Latina students often mentioned that in their culture, the first-born child to a family was supposed to be a boy. So 
Table 14 Correlations for MSLQ subsection on self-efficacy for learning and performance motivation

\begin{tabular}{lllllllll}
\hline Factors & 1 & 2 & 3 & 4 & 5 & 6 & 7 & 8 \\
\hline 1. I believe I will earn an excellent GPA in my STEM major. & - & 0.37 & -0.04 & 0.02 & $0.71^{* *}$ & $0.52^{* *}$ & 0.07 & $.60^{* *}$ \\
2. I'm certain I can understand the most difficult material taught in my STEM major. & 0.41 & - & $0.40^{*}$ & $0.58^{* *}$ & $0.73^{* *}$ & $0.58^{* *}$ & 0.29 & $0.77^{* *}$ \\
3. I'm confident I can understand the basic concepts taught in my STEM major & 0.20 & $0.63^{* *}$ & - & 0.18 & 0.22 & $.42^{*}$ & $0.53^{* *}$ & 0.32 \\
4. I am confident I can understand the most complex material presented by the faculty in & 0.28 & $0.80^{* *}$ & $0.52^{*}$ & - & $0.43^{*}$ & 0.39 & $0.44^{*}$ & 0.36 \\
my STEM major. & & & & & & \\
5. I'm confident I can do an excellent job on the assignments and tests in my STEM major. & 0.23 & $0.49^{*}$ & $0.51^{*}$ & $0.50^{*}$ & - & $0.76^{* *}$ & $0.39^{*}$ & $0.87^{* *}$ \\
6. I expect to do well in my STEM major. & 0.10 & 0.25 & 0.3 & 0.28 & $0.71^{* *}$ & - & 0.38 & $0.76^{* *}$ \\
7. I'm certain I can master the skills being taught in my STEM major. & -0.05 & $0.65^{* *}$ & $0.55^{* *}$ & $0.62^{* *}$ & $0.80^{* *}$ & $0.66^{* *}$ & - & 0.29 \\
8. Considering the difficulty of the courses, the teachers, and my skills, I think I will do well & 0.31 & $0.46^{*}$ & $0.65^{* *}$ & 0.35 & $0.69^{* *}$ & $0.75^{* *}$ & $0.62^{* *}$ & -
\end{tabular}

Notes: Correlations for White students $(n=26)$ are presented above the diagonal, and correlations for minority students $(n=21)$ are presented below the diagonal. *Means correlation is significant to the 0.05 level, and ** means correlation is significant to the 0.01 level

when they, a girl, were the first born, they would often take on the boy's traditional role of helping their fathers, which would often spark their interest in STEM careers. This same cultural pressure for Latino boys to follow in their father's footsteps could generate significant pressure on these students to earn good grades to be able to provide for their families. Thus, cultural expectations of gender roles could be the reason that minority students, in Fig. 6, thought that grades were more important to their male peers than to them.

On the questionnaire, the students often ranked internal self-concept and instrumental motivation factors more highly in all of the question groupings as the reason behind their choice to select and then persist in their STEM major. Therefore, it was not surprising that students rarely called out the contributing factors of pre-collegiate experiences, which are more closely associated with intrinsic process motivation, as the primary factor influencing their STEM enrollment decision. When looking at all of the factors influencing enrollment in a STEM major (Fig. 2), findings from the focus groups are supported where many students cited early experiences with STEM including encouragement from family and teachers as being influencers in their decisions to pursue and persist in a STEM field. It was also interesting to see that no minority students mentioned that their school counselor encouraged them to major in STEM. The authors can speculate that the lack of encouragement could be from several sources: a cultural expectation that minority women do not belong in STEM, which could result in these majors not being mentioned during advising or being discouraged; or an indication that these women did not spend much time with their school counselors. However, as this study did not ask if they were discouraged by school counselors or how much they consulted their counselors, a firm conclusion as to why school counselors did not appear to encourage this group of minority women to major in STEM cannot be reached.

\section{Motivational factors attributed to influencing STEM enrollment}

Being motivated by a challenge matches the profile of a highly motivated and determined individual as well as embodying internal self-concept motivation. The students in this study frequently selected internal selfconcept and instrumental motivation factors in their decisions to choose and persist in STEM majors. These findings were supported in the focus groups by students desiring to stand out in their field or changing majors to STEM to have better career opportunities. Thus, the study findings across demographics are in line with other research on female persistence in STEM majors (Ackerman et al. 2013).

Student motivations do reflect their cultural backgrounds with the minority students reporting a greater influence from family support in their motivation to persist versus the White students at this institution. As noted in the results, this difference between these two student groups was the only external self-concept motivation with statistical significance amongst the various motivations to persist in their major. Family support was also the only external self-concept motivation to be cited by students positively in the focus groups, which stands in contrast to another external self-concept motivation factor: the opinion of friends. Focus group discussion did reveal that students' non-STEM major female friends did not understand their desire to pursue their majors. For example, after accompanying one of the participants on a community service project hosted by a maledominated STEM student group, one friend asked the participant how she could deal with all of the guys. In the questionnaire, all of the students indicated that they are least likely to find motivation to persist in their major from their friends (Fig. 4). Nearly a third of the 
students indicated that this statement was untrue of them to some degree (38\% of the minority students and $23 \%$ of the White students). Having so many students disassociate with this statement is likely a result of American culture, where student's friends may not understand why they want to pursue a male-dominated field as was illustrated in focus group discussion.

Students in the focus groups were asked to describe their personalities in order to explore any personal characteristics that might explain their choice of study, or persistence in remaining in the field of study. Although no direct discussion of altruism was brought up, students did speak of their desire to contribute to society through their organizational skills and desire to improve things for people and organizations. Although helping others was not a particularly high or low ranking factor in the survey results for students choosing their major (Fig. 3), altruism was ranked much more highly when asked as a yes/no question about positively affecting society (Fig. 6). When asked if it was a reason for choosing their majors (Fig. 3), most students indicated the statement was true of them to some degree (90 and $84 \%$ above neutral responses for minority and White students, respectively) and no students said it was not true of them to any degree. While more White students, by percentage, where neutral on altruism as a factor in choosing their major, they had the highest agreement rate when asked the yes/no question about positively affecting society (Fig. 6). This difference could be that these students perceive the concept of helping others as more of a hands-on activity, such as volunteerism or nursing, versus positively affecting society, which they could perceive as resulting from a STEM research breakthrough, such as a new vaccine or medical device.

The students participating in the focus group were very open and honest in reflecting on their emotions, perceptions, and interests. While several expressed the observation that classes were challenging and that they struggled, they also expressed self-confidence in their ability to work hard and eventually figure things out, an internal self-concept motivation factor. Most agreed that many times lower expectations were placed upon them by their peers and sometimes faculty because they are women, a negative external self-concept motivation factor. Gabriela discussed the added pressure of doing well since she represents women in STEM and that, often, this would shake her self-confidence. In Fig. 7 of the results, minority students had the same level of self-efficacy (5.77) for both their expectation of understanding basic and difficult concepts in their majors. White students, however, had a drop of over half a point (6.27 to 5.69) between these two questions. Interestingly, the minority students felt more confident in their abilities to understand complex topics in their majors (5.95), which was a similar but higher rating than the White students (5.85). The minority students, thus, are trending towards having a fairly consistent level of self-efficacy in their abilities to grasp the material in their major, even if their expectations of receiving a good GPA are lower than all other topics in this question grouping. None of the differences in response between the two groups, however, was statistically significant to the $95 \%$ confidence level. For both the White and minority students, their self-efficacy in doing well in their major is much higher than their self-efficacy in earning an excellent GPA (1.09 and 0.81 points higher for minority students and White students, respectively). This separation of the concepts of doing well and an excellent GPA could be part of the reason that these students are succeeding when other female students might leave. They are bucking the statistics that indicate female students hold themselves to a higher grade standard than their male peers in judging whether their performance is good (Concannon and Barrow 2009).

\section{Conclusions}

This study contributes to the field by revealing a more in-depth account of what experiences women credit for influencing the development of their career interests and their motivation to persist in studying science, technology, engineering and mathematics (STEM). This study includes a substantial Latina point of view (with over $45 \%$ of participants identifying as minority or multi-racial students).

The first research question that drove this study was to examine what factors contribute to the interest development and motivational drive to persist of college women in STEM. Quantitative analysis of survey data revealed that the factors of "career options" and "family support" emerged as significant sources of motivation to persistence in STEM majors for the minority-rich student population in this study, as it was seen as a reflection of culture for the minority students in the study. Family support and attitudes regarding these female students persisting in STEM fields were frequently discussed in the focus groups. In particular, pre-collegiate experiences were often cited by the focus group participants as pivotal in their interest development. These findings underscore the importance of the many outreach STEM programs targeting $\mathrm{K}-12$ students, especially women and minorities, in widening the STEM pipeline.

The second research question examined in what ways, if any, Latina and African American STEM students differ in their interest development and motivations to persist in STEM from their White female peers. Focus groups revealed the particular importance 
of family expectation as a motivation to pursue and persist in a STEM career; a difference that was also shown with statistical significance in the survey results. Thus, outreach efforts that inform parents and families about the opportunities in STEM careers and illustrate that these careers are for everyone-not just the stereotypical white male-could result in a cultural shift that encourages more women and minorities to pursue STEM careers. Ethnicity may also be correlated to socio-economic status. As such, the strong preference for career options as the primary factor in deciding to enroll in a STEM major could be a result of the large number $(41 \%)$ of respondents who self-identified as being either from socio-economic lower or lower-middle class backgrounds. These students could view the famously higher wages of STEM careers as a pathway to socio-economic mobility. To explore this perspective, future work will also examine students' responses broken down by socio-economic background data.

The survey and focus group guide used for this study were based on validated instruments but used modified language to address the specific goals of this study as well as including additional, non-validated, questions. Further use of these tools is recommended in order to validate their results, including use with different populations. Finally, researchers in this area are recommended to employ a mixed methods approach to be able to triangulate between the quantitative results of questionnaire results and deeper qualitative insights. The qualitative analysis of the focus group content begins to reveal the rich tapestry of experiences, influences, and values that women bring with them to their undergraduate academic journeys.

\section{Acknowledgements}

The authors gratefully acknowledge that the support for this work was provided by the National Science Foundation Award No. DUE-1431578. Any opinions, findings, and conclusions or recommendations expressed in this material are those of the authors and do not necessarily reflect the views of the National Science Foundation.

\section{Authors' contributions}

Both authors designed the survey methodology, edited the questionnaire instrument, and conducted the focus groups. The first author led in the quantitative analysis of the resulting questionnaire data, and the second author led in the qualitative analysis of the data. Both authors contributed to the literature and discussion sections.

\section{Competing interests}

The authors declare that they have no competing interests.

\section{Consent for publication}

This manuscript does not include images or videos relating to individual participants. Notes were recorded and transcribed of spoken comments and each participant signed a written informed consent form allowing the use of their input for educational publication. All names used in this manuscript are pseudonyms in order to protect respondent confidentiality.

\section{Ethics approval and consent to participate}

We confirm that our research methodology involved human subjects and was reviewed and approved in 2014 by the IRB Regulatory Manager of the Office of
Research Integrity and Compliance at Texas State University at the time. Since our research is ongoing, a recent review of revisions has kept the approval current (approved application no. 2017150), and the most recent approval was given by Dr. Jon Lasser, IRB Committee Chair and Ms. Monica Gonzales, the current IRB Regulatory Manager of the Office of Research Integrity and Compliance at Texas State University effective through 10/31/17.

\section{Publisher's Note}

Springer Nature remains neutral with regard to jurisdictional claims in published maps and institutional affiliations.

Received: 16 August 2016 Accepted: 22 February 2017

Published online: 30 March 2017

\section{References}

Ackerman, P. L., Kanfer, R., \& Beier, M. E. (2013). Trait complex, cognitive ability, and domain knowledge predictors of baccalaureate success, STEM persistence, and gender differences. J Educational Psychology, 105(3), 911-927.

Adams, J. S. (1963). Towards an understanding of inequality. J Abnormal and Normal Social Psychology, 67, 422-436.

Alderfer, C. (1972). Existence, relatedness, and growth. New York: Free Press.

Azevedo, R. (2005). Using hypermedia as a metacognitive tool for enhancing student learning?: the role of self-regulated learning. Educational Psychologist, 40(4), 199-209.

Backer, P. R., \& Halualani, R. T. (2012). Impact of Self-efficacy on Interest and Choice in Engineering Study and Careers for Undergraduate Women Engineering Students Paper presented at 2012 ASEE Annual Conference \& Exposition, San Antonio, Texas. https://peer.asee.org/21475.

Bandura, A. (1995). Self-efficacy in changing societies. Cambridge: Cambridge University Press.

Bandura, A., \& Locke, E. A. (2003). Negative self-efficacy and goals effects revisited. Journal of Applied Psychology, 88, 87-99.

Barbuto, J. E., \& Scholl, R. W. (1998). Motivation sources inventory: development and validation of new scales to measure an integrative taxonomy of motivation. Psychological Reports, 82, 1011-1022.

Bettinger, E. P., \& Long, B. T. (2005). Do faculty serve as role models? the impact of instructor gender on female students. American Economic Review, 95(2), 152-157.

Carnevale, A. P., Smith, N., \& Strohl, J. (2010). Help wanted: projections of jobs and education requirements through 2018. Washington, DC: Center on Education and the Workforce.

Chang, M. J., Sharkness, J., Newman, C. B., \& Hurtado, S. (2014). What matters in college for retaining aspiring scientists and engineers from underrepresented racial groups. J Research in Science Teaching, 51(5), 555-580.

Concannon, J. P., \& Barrow, L. H. (2009). A cross-sectional study of engineering students' self-efficacy by gender, ethnicity, year, and transfer status. J. Sci. Educ. Technol., 18(2), 163-172.

Connor, J. M. \& Serbin, L. A. (1977). Behaviorally- Based Masculine and Feminine Activity Preferences Scales for Preschoolers: Correlates wirh Other Classroom Behaviors and Cognitive Tests. Child Development, 48, 1411-1416.

Creswell, J. W., \& Plano Clark, V. L. (2011). Designing and conducting mixed methods research (2nd ed.). Thousand Oaks: Sage

Cronbach, L. J. (1951). "Coefficient alpha and the internal structure of tests". Psychometrika. 16 (3): 297-334. doi:10.1007/bf02310555

Daly, J., Kellehear, A., \& Gliksman, M. (1997). The public health researcher: a methodological approach. Melbourne: Oxford University Press.

Denissen, J. H., Zarrett, N. R., \& Eccles, J. S. (2007). "I like to do it, I'm able, and I know I am": longitudinal couplings between domain-specific achievement, self-concept, and interest. Child Development, 78, 430-447.

Dewey, J. (1913). Interest and effort in education. Boston: Riverside.

Eccles, J. S. (1987). Gender roles and Women's achievement-related decisions. Psychology of Women Quarterly, 11(2), 135-172. doi:10.1111/j.1471-6402.1987. tb00781.x.

Edzie, R. L., (2014) Exploring the Factors that Influence and Motivate Female Students to Enroll and Persist in Collegiate STEM Degree Programs: A Mixed Methods Study. Ph.D. diss., University of Nebraska.

Espinosa, L. L. (2011). Pipelines and pathways: women of color in undergraduate STEM majors and the college experiences that contribute to persistence. Harvard Educational Review, 81, 209. 
Gabay-Egozi, L. Shavit, Y. and Yaish, M. (2015), 'Gender Differences in Fields of Study: The Role of Significant Others and Rational Choice Motivations,' European Sociological Review, 31(3), 284-297.

Griffith, A. L. (2010). Persistence of women and minorities in STEM field majors: Is it the school that matters? [Electronic version]. Retrieved January 11, 2017, from Cornell University, School of Industrial and Labor Relations site: http:/ digitalcommons.ilr.cornell.edu/workingpapers/122/.

Grissom, R. J., \& Kim, J. J. (2005). Effect Sizes for Research: A Broad Practical Approach. Mahwah: Lawrence Erlbaum.

Guay, F., Chanal, J., Ratelle, C. F., Marsh, H. W., Larose, S., \& Boivin, M. (2010). Intrinsic, identified, and controlled types of motivation for school subjects in young elementary school children. British I Educational Psychology, 80(4), 711-735.

Hernandez, P. R., Schultz, PW., Estrada, M., Woodcock, A., \& Chance, R. C. (2013). Sustaining optimal motivation: A longitudinal analysis of interventions to broaden participation of underrepresented students in STEM. Journal of Educational Psychology, 105(1). doi:10.1037/a0029691.

Herzberg, F. (1966). Work and the nature of man. New York: The World Publishing Company.

Hill, C., Corbett, C., and St. Rose, A., (2010) Why So Few?: Women in Science, Technology, Engineering, and Mathematics. Available at: http://www.aauw.org/ research/why-so-few/

Hughes, R. M., (2010) The Process of Choosing Science, Technology, Engineering and Mathematics Careers by Undergraduate Women: A Narrative Life History Analysis. Dissertation. Florida State University. Available at: http://diginole.lib. fsu.edu/islandora/object/fsu\%3A254222.

Jacobs, J., Lanza, S., Osgood, D. W., Eccles, J. S., \& Wigfield, A. (2002). Ontogeny of children's selfbeliefs: Gender and domain differences across grades one through 12. Child Development, 73, 509-527.

Jensen, L. A. (2011). Bridging cultural and developmental approaches to psychology: new syntheses in theory, research and policy. New York: Oxford University Press.

Krapp, A., \& Lewalter, D. (2001). Development of interests and interest-based motivational orientations: a longitudinal study in vocational school and work settings. In S. Volet \& S. Jarvela (Eds.), Motivation in learning contexts: theoretical advances and methodological implications (pp. 209-232). New York: Elsevier.

Krueger, R. A. (1994). Focus groups: a practical guide for applied research (2nd ed.). Thousand Oaks: Sage Publications.

Krueger, R. A., \& Casey, M. A. (2000). Focus groups: a practical guide for applied research (3rd ed.). Thousand Oaks: Sage Publications.

Lent, R. W., Brown, S. D., Schmidt, J., Brenner, B., Lyons, H., \& Treistman, D. (2003). Relation of contextual supports and barriers to choice behavior in engineering majors: Test of alternative social cognitive models. Journal of Counseling Psychology, 50, 458-465.

Lent, R. W., Lopez, A. M., Lopez, F. G., \& Scheu, H. (2008). Social cognitive career theory and the prediction of interests and choice goals in the computing disciplines. J Vocational Behavior, 73, 52-62. doi:10.1016/j.jvb. 2008.01.002.

Leonard, N. H., Beauvais, L. L., \& Scholl, R. W. (1999). Work motivation: the incorporation of self-conceptbased processes. Human Relations, 52(8), 969-998.

Lindlof, T. R., \& Taylor, B. C. (2002). Qualitative communication research methods. Thousand Oaks: Sage Publications.

Locke, E. A., \& Latham, G. P. (1990). A theory of goal setting and task performance. Upper Saddle River: Prentice Hall.

Longwell-Grice, R., \& Longwell-Grice, H. (2007). Testing Tinto: how do retention theories work for first-generation, working-class students? J College Student Retention, 9(4), 407-420.

Lowell, B. L., \& Salzman, H. (2007). Into the eye of the storm: assessing the evidence on science and engineering education, quality, and workforce demand. Washington, DC: The Urban Institute. Available at http://www.urban.org/ research/publication/eye-storm.

Martinez Ortiz, A. \& Sriraman, V. (2015). Exploring faculty insights into why undergraduate college students leave STEM fields of study: A three-part organizational self-study. American Journal of Engineering Education, 6(1), 43-60.

Maslow, A. H. (1943). A theory of human motivation. Psychological Review, 50(4), 370-96.

McCelland, D. C. (1985). How motives, skills, and values determine what people do. American Psychologist, 40(7), 812-825. doi:10.1037/0003-066X.40.7.812.
Myers, J. M., \& Well, A. D. (1995). Research design and statistical analysis. Mahwah: Lawrence Erlbaum Publishers.

National Science Foundation (2016). Science and Engineering Indicators 2016 (NSB-2016-1) Accessed 15 Oct 2016 at https://nsf.gov/statistics/2016/ nsb20161/\#/report.

National Science Foundation, National Center for Science and Engineering Statistics. (2015). Women, minorities, and persons with disabilities in science and engineering: 2015. Special report NSF 15-311. Arlington: National Science Foundation. Available at http://www.nsf.gov/statistics/wmpd/.

Noel-Levitz, (2012). 2012 National Freshman Attitudes Report, Coralville: NoelLevitz, Inc. Available at https://www.noellevitz.com/papers-research-highereducation/2012/2012-national-freshman-attitudes-report.

Ong, M., Wright, C., Espinosa, L. L., \& Orfield, G. (2011). Inside the double bind: a synthesis of empirical research on undergraduate and graduate women of color in science, technology, engineering and mathematics. Harvard Educational Review, 81, 172.

Pett, M. A. (1997). Nonparametric statistics for health care research: Statistics for small samples and unusual distributions. Thousand Oaks: Sage Publications.

Pintrich, P. R., \& DeGroot, E. V. (1990). Motivational and self-regulated learning components of classroom academic performance. J Educational Psychology, 82, 33-40.

Pintrich, P. R., \& Schunk, D. H. (2002). Motivation in education: theory, research and applications. Englewood Cliffs: Prentice Hall.

Pintrich, P., Smith, D., Garcia, T., \& McKeachie, W. (1991). A manual for the use of the motivated strategies for learning questionnaire (MSLQ). Ann Arbor: National Center for Research to Improve Post-secondary Teaching and Learning.

Pintrich, P. R., Smith, D. A. F., Garcia, T., \& McKeachie, E. J. (1993). Reliability and predictive validity of the motivated strategies for learning questionnaire (MSLQ). Educational and Psychological Measurement, 53, 801-813.

President's Council of Advisors on Science and Technology, (2012) Engage to Excel: Producing One Million Additional College Graduates with Degrees in Science, Technology, Engineering, and Mathematics. Available at: https:/ obamawhitehouse.archives.gov/administration/eop/ostp/pcast/news.

Renninger, K. A., \& Wozniak, R. (1985). Effect of interest on attentional shift, recognition, and recall in young children. Developmental Psychology, 21, 624-632.

Sadoski, M., \& Paivio, A. (2001). Imagery and text: a dual coding theory of reading and writing. Mahwah: Lawrence Erlbaum Associates.

Schiefele, U. (1999). Interest and learning from text. Scientific Studies of Reading, 3, 257-279.

Scholl, R.W. (2015) Work motivation overview. Retrieved October 15, 2015 from: https:/www.researchgate.net/profile/Richard_Scholl.

Seidman, A. (2005). Commentary: defining retention. J College Student Retention: Research, Theory \& Practice, 6(2), 129-137.

Seymour, E. (1995). The loss of women from science, mathematics, and engineering undergraduate majors: An explanatory account. Science Education, 79, 437-473.

Silvia, P. J. (2006). Exploring the psychology of interest. New York: Oxford University Press. Skinner, B.F., (1953) Science and Human Behavior, New York: The Free Press Download available at the B. F. Skinner Foundation web site: BFSkinner.org.

Spady, W. G. (1971). Dropouts from higher education: toward an empirical model. Interchange, 2(3), 38-62.

Szelényi, K., Denson, N., \& Inkelas, K. (2013). Women in STEM Majors and Professional Outcome Expectations: The Role of Living-Learning Programs and Other College Environments. Research in Higher Education, 54(8), $851-$ 873. Retrieved from http://www.jstor.org/stable/24571767.

Tabachnick, B. G., \& Fidell, L. S. (2013). Using multivariate statistics (6th ed.). Boston: Pearson.

Teitelbaum, M. S. (2014). Falling behind?: boom, bust, and the global race for scientific talent. Princeton: Princeton University Press.

Thompson, B. (2004). Exploratory and confirmatory factor analysis: understanding concepts and applications. Washington, DC: American Psychological Association.

Tinto, V. (2006). Research and practice of student retention: what next? J College Student Retention, 8(1), 1-20

Vroom, V.H., (1964). Work and Motivation. New York: John Wiley \& Sons, Inc. 